\title{
Molecular Genetics of Rice Root Development
}

\author{
J. Rebouillat • A. Dievart • J. L. Verdeil • J. Escoute • \\ G. Giese • J. C. Breitler • P. Gantet • S. Espeout • \\ E. Guiderdoni • C. Périn
}

Received: 9 July 2008 / Accepted: 27 October 2008 / Published online: 23 December 2008

(C) Springer Science + Business Media, LLC 2008

\begin{abstract}
Plant roots have a large range of functions, including acquisition of water and nutrients, as well as structural support. Dissecting the genetic and molecular mechanisms controlling rice root development is critical for the development of new rice ideotypes that are better adapted to adverse conditions and for the production of sustainably achieved rice yield potential. Most knowledge
\end{abstract}

J. Rebouillat and A. Dievart contributed equally to this work.

J. Rebouillat · A. Dievart · J. L. Verdeil · J. Escoute · G. Giese •

J. C. Breitler · P. Gantet $\cdot$ S. Espeout $\cdot$ E. Guiderdoni ·

C. Périn $(\square)$

UMR DAP, CIRAD, TA-A96 /03 Avenue Agropolis,

34398 Montpellier, France

e-mail: perin@cirad.fr

J. Rebouillat

e-mail: jrebouillat@hamamatsu.fr

A. Dievart

e-mail: anne.dievart@orange.fr

J. L. Verdeil

e-mail: verdeil@cirad.fr

J. Escoute

e-mail: escoute@cirad.fr

G. Giese

e-mail: Guenter.Giese@mpimf-heidelberg.mpg.de

J. C. Breitler

e-mail: breitler@cirad.fr

P. Gantet

e-mail: pascal.gantet@univ-montp2.fr

S. Espeout

e-mail: Sandra.espeout@cirad.fr

E. Guiderdoni

e-mail: guiderdoni@cirad.fr regarding the gene networks involved in root development has been accumulated in the model dicotyledon plant species Arabidopsis thaliana. Rice, the model monocotyledon species, presents several singularities compared to $A$. thaliana, including a root architecture characterized by a fibrous root system comprising five types of embryonic and postembryonic roots. The anatomy and morphology of the rice root system, which is typical for a cereal, differs from that of $A$. thaliana, for instance, by the presence of a lysigenous cortex and additional cell layers compared to the dicotyledon model. Moreover, the structure and functions of the root apical meristem (RAM) of rice are distinct from those of $A$. thaliana. Recently, several rice root mutants have been identified via forward or reverse genetics, and these will aid in forming hypothesis to characterize either the divergence or conservation of genetic pathways relative to A. thaliana. Furthermore, these mutants will help to identify key genes in rice roots that may be missing in $A$. thaliana. This review summarizes both classical and recent data concerning the molecular genetics of rice root development, including root anatomy and morphology, RAM structure, RAM patterning, and root mutants.

Keywords Oryza sativa L. · Rice · Root apical meristem · Mutants $\cdot$ Molecular genetics

\section{Introduction}

The root system performs essential functions during plant development, including anchoring and water and nutrient uptake. For instance, a deep, thick, and branched root system is correlated with better survival under adverse conditions, such as water or nutrient deficits. The structure of a root system is determined by an endogenous genetic 
program as well as by external environmental factors, including biotic and abiotic stresses. The high adaptive plasticity of root development complicates the genetic dissection of genes controlling root structure variation and represents a bottleneck for the efficient selection of specific root ideotypes [15]. Genetic control of root development has been studied mainly through quantitative trait loci (QTL) analysis, and a wide range of QTLs associated with small-medium effects on root biomass, root length, root number (either under control or abiotic stress conditions) has been identified in rice (see for instance [48, 49, 63, 74, 85, 97-99]; however, no root mutants have been characterized at the molecular level. Fine mapping of root QTLs is complicated by the high plasticity of root development, which, in turn, necessitates accurate phenotyping using a large mapping population. This explains why no root QTLs has been cloned in rice; the same holds true in A. thaliana, with a single exception [82]. Recently, several monogenic root-specific mutants were identified in rice (Table 1). They can be roughly classified into distinct mutant categories, i.e., affected in root formation, root differentiation, RAM patterning, RAM specification, initial cell behavior, and auxin-related mutants. Reverse genetics has also been used to analyze the functions of key root developmental genes in rice that were previously identified in A. thaliana (for a review, see [81]). In this article, we review the present knowledge about the molecular genetics of root development in the monocot model plant, rice, and compare several specific processes with what is known for the dicot model, A. thaliana. We also emphasize the cellular aspects of rice root development and suggest future directions to decipher specific genetic and molecular mechanisms involved in root development in rice.

\section{Root architecture}

The rice root system consists of different types of roots

Like in other cereals, root architecture in rice is composed of several embryonic and postembryonic types of roots. The rice root system is comprised of five root types, including the embryonic roots as well as the postembryonic roots: the radicle, the embryonic crown roots, the postembryonic crown roots, the large lateral roots, and the small lateral roots [33] (Fig. 1). The radicle first emerges by breaking the coleorhiza (Fig. 1a). Two to 3 days after germination, five embryonic crown roots emerge from the coleoptilar node by breaking the sheath (Fig. 1a) during the first and second leaf emergence stages.

Later, adventitious postembryonic crown roots, also called nodal roots, emerge from the nodes on the stem and tillers arranged in one or two rows (Fig. 1b). For example, more than 100 crown roots are present 40 days after germination in cv Nipponbare plants grown under hydroponic conditions, forming a fibrous root system (Fig. 1b). Root ramification is also partially responsible for this fibrous architecture. Indeed, lateral rice roots can appear on any primary root, including embryonic and crown roots, and can be classified into two main anatomical types [77] (Fig. 1a, c). Thin small lateral roots exhibiting determinate growth are by far the most numerous (Fig. 1a). A few large lateral roots, which are thinner in diameter than primary roots, can also be observed. They display indeterminate growth and can also bear small lateral roots (Fig. 1c). Moreover, the small lateral roots elongate laterally, whereas the large lateral roots elongate downward, suggesting that the small lateral roots do not respond to gravity. Higher orders of branching can also be observed in the large lateral roots of the crown roots that emerge at later growth stages [55]. Small lateral roots exhibit determinate growth and never bear lateral roots, whereas all other root types have indeterminate growth and bear numerous lateral roots, suggesting a different function for these two types of lateral roots.

Root and shoot development is synchronized and depends on environmental conditions

The concept of a phytomer was established 45 years ago [56]. A phytomer is a developmental unit composed (in rice) of a leaf, a node to which the leaf is attached, an axillary bud, which will eventually give rise to a tiller, and two rings of crown roots formed above and under each node and called the "upper root" and the "lower root" (Fig. 2a). The coleoptilar phytomer is, by convention, the zeroth phytomer (Fig. 2b). By using the developmental stage of the shoot as a reference, which is evaluated by the phyllochron (time interval between the initiation of two successive leaves on the shoot) index, it is possible to assay the developmental stage of crown root emergence (except for the crown roots of the first phytomer), which is closely related to leaf emergence $[25,56]$. The relationship between the internode, the node, and the position of embryonic roots is shown in Fig. 2b. The radicle belongs to the coleoptilar phytomer, and embryonic crown roots belong to the first phytomer (Fig. 2b). When a visible leaf blade emerges from the Nth phytomer, upper and lower crown roots begin to grow and emerge at the $N$-third phytomer (Fig. 2c). The same relationship also exists for lateral roots (Fig. 2c). In summary, secondary roots emerge during the growth of the leaf blade of the fourth phytomer, tertiary roots emerge during emergence of the fifth phytomer, and so on [25]. Postembryonic root emergence proceeds acropetally, and the mature rice root system is mainly made up of crown roots represented by diverse ages, which depend on the 
Table 1 Specific Rice Mutants Affected in Several Aspects of Root Development

\begin{tabular}{|c|c|c|c|c|}
\hline Gene & Name & Molecular function & Refs & Phenotype \\
\hline$R A L 1$ & RADICLELESS 1 & ND & $\begin{array}{l}\text { Scarpella et al. } \\
\text { [80] }\end{array}$ & $\begin{array}{l}\text { Radicle formation, vascular } \\
\text { development, procambium }\end{array}$ \\
\hline$R A L 2$ & RADICLELESS 2 & ND & Hong et al. [35] & \\
\hline$A R L 1$ & ADVENTITIOUS ROOTLESS 1 & LOB Class I & Liu et al. [67] & Crown rootless \\
\hline$C R L 1$ & CROW ROOT LESS 1 & LOB Class I & Inukai et al. [39] & Crown rootless \\
\hline$C R L 2$ & CROW ROOT LESS 2 & ND & Inukai et al. [37] & Crown rootless \\
\hline LRT1/RM109 & LATERAL ROOT LESS 1 & ND & Chhun et al. [6] & $\begin{array}{l}\text { Lateral rootless, resistance } \\
\text { to } 2,4-\mathrm{D} \text {, altered root gravity }\end{array}$ \\
\hline$L R T 2$ & LATERAL ROOT LESS 2 & ND & Wang et al. [92] & $\begin{array}{l}\text { Lateral rootless, resistance to } \\
2,4-\mathrm{D} \text {, altered root gravity }\end{array}$ \\
\hline RH2 & ROOT HAIRLESS 2 & ND & Suzuki et al. [88] & Root hairless \\
\hline$S R T 1 / R M 1 / R M 2$ & SHORT-ROOT 1 & ND & $\begin{array}{l}\text { Ichii and Ishikawa } \\
\text { [36] }\end{array}$ & Reduced root length \\
\hline SRT2/LM10 & SHORT-ROOT 2 & ND & Liang and Ichii [65] & Root cell length \\
\hline SRT3 & SHORT-ROOT 3 & ND & Yi et al. [96] & ND \\
\hline SRT4 & SHORT-ROOT 4 & ND & $\begin{array}{l}\text { Ichii and Ishikawa } \\
\text { [36] }\end{array}$ & ND \\
\hline SRT5 & SHORT-ROOT 5 & ND & Yao et al. [95] & $\begin{array}{l}\text { Sugar deficiency, inhibition } \\
\text { of root length }\end{array}$ \\
\hline SRT6 & SHORT-ROOT 6 & ND & Yao et al. [94] & $\begin{array}{l}\text { ABA insensitive, inhibition } \\
\text { of early root elongation }\end{array}$ \\
\hline$A L F 1 / A E M 1$ & $\begin{array}{l}\text { ALTERED LATERAL } \\
\text { ROOT FORMATION } 1\end{array}$ & ND & Debi et al. [16] & $\begin{array}{l}\text { Shorter lateral roots and } \\
\text { proliferation of lateral roots }\end{array}$ \\
\hline$R R L 1$ & REDUCED ROOT LENGTH & ND & Inukai et al. [38] & $\begin{array}{l}\text { Reduced root length for } \\
\text { mature cells }\end{array}$ \\
\hline$R R L 2$ & REDUCED ROOT LENGTH & ND & Inukai et al. [38] & $\begin{array}{l}\text { Reduced root length, meristem } \\
\text { size, RAM cell divisions }\end{array}$ \\
\hline$R T 1$ & ROOT GROWTH INHIBITING 1 & ND & $\begin{array}{c}\text { Fustuhara and } \\
\text { Kitano [27] }\end{array}$ & Root elongation, root number \\
\hline$A R M 1$ & AUXIN RESISTANT MUTANT 1 & ND & Chhun et al. [7] & $\begin{array}{l}\text { Resistance to } 2,4-\mathrm{D} \text {, fewer lateral } \\
\text { roots, shorter roots }\end{array}$ \\
\hline$A R M 2$ & AUXIN RESISTANT MUTANT 2 & ND & Chhun et al. [7] & $\begin{array}{l}\text { Resistance to 2,4-D, fewer lateral } \\
\text { roots, auxin uptake }\end{array}$ \\
\hline DES & DIAMETER OF SEMINAL ROOT & ND & Wan et al. [91] & ND \\
\hline OSHOX1 & ORYZA SATIVA HOMEOBOX 1 & $\begin{array}{l}\text { HD-Zip transcription } \\
\text { factor }\end{array}$ & Meijer et al. [69] & Procambium cell fate commitment \\
\hline GLR3.1 & GLUTAMATE RECEPTOR 3.1 & Glutamate receptor & Li et al. [64] & QC, RAM mitotic activity \\
\hline OSSCR & ORYZA SATIVA SCR & $\begin{array}{l}\text { GRAS transcription } \\
\text { factor }\end{array}$ & Kamiya et al. [46] & $\begin{array}{l}\text { QC, endodermis asymmetric } \\
\text { cell division }\end{array}$ \\
\hline$Q H B$ & $\begin{array}{l}\text { QUIESCENT CENTER SPECIFIC } \\
\text { HOMEOBOX }\end{array}$ & HB transcription factor & Kamiya et al. [47] & RAM QC \\
\hline OSCYT-INV1 & ORYZA SATIVA CYT-INV1 & Alkaline/neutral invertase & Jia et al. [41] & Root cell length reduced \\
\hline OSGNAI & $\begin{array}{l}\text { ORYZA SATIVA GLUCOSAMINE-6-P } \\
\text { ACETYLTRANSFERASE }\end{array}$ & $\begin{array}{l}\text { glucosamine-6-P } \\
\text { acetyltransferase }\end{array}$ & Jiang et al. [44] & Root elongation \\
\hline
\end{tabular}

$N D$ not determined

phytomer of origin. Crown root primordia formation is under genetic control and is a normal developmental process; emergence, in contrast, is controlled by environmental conditions. Crown root emergence is induced in rice following submergence [70]. Moreover, the emergence of the crown roots is also stimulated upon flooding of the plant and is mediated by ethylene [70].

\section{Root anatomy}

The radial anatomy of the rice roots reflects an adaptation to semiaquatic life conditions

The radial anatomy of rice roots typifies semiaquatic plants with specialized tissues that permit root growth during 
Fig. 1 Root architecture. (A) Morphology of the embryonic root system of seedling cv Nipponbare, 1 week after germination. $(B)$ Morphology of the rice root system 40 days after germination. $(C)$ Detail of a crown root 40 days after germination. $\mathrm{ra}$, radicle; ecr, embryonic crown root; $\mathrm{cr}$, crown root; $l l r$, large lateral root; slr, small lateral root; scale bars $(A) 1 \mathrm{~cm}$, (B) $5 \mathrm{~cm},(C) 1 \mathrm{~cm}$.

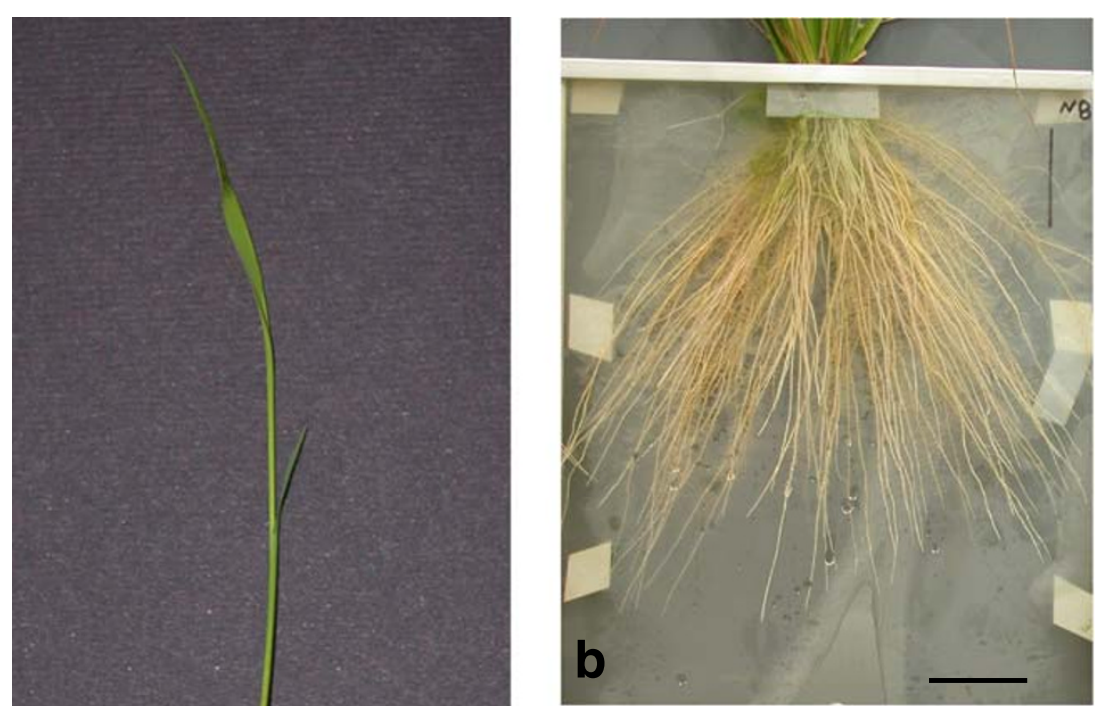
ra ecr

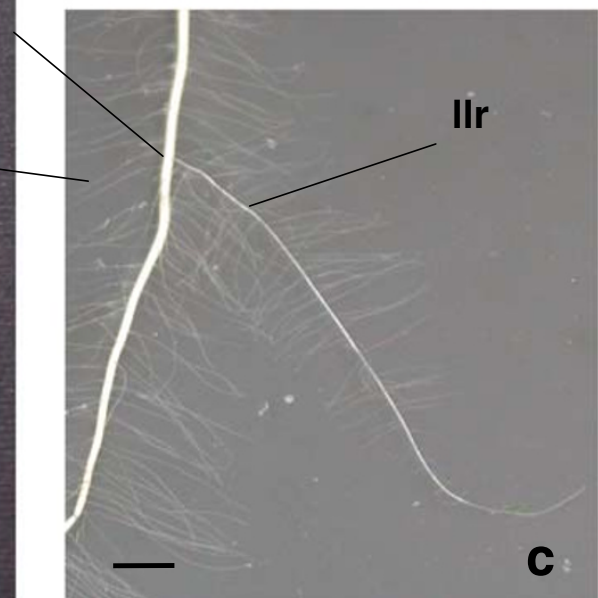

flooding conditions: from the outside in, the epidermis, the ground tissue made of four tissues (exodermis, sclerenchyma cell layer, midcortex or mesodermis, and endodermis), and the central cylinder are present (Fig. 3a, b, d). The epidermis, exodermis, sclerenchyma, and endodermis, each of which consists of a single layer of cells, are found in all root types. Beneath the epidermis, the exodermis is the outermost layer that protects old roots when the epidermis collapses; in this scenario, the exodermis plays functions like the epidermis with regard to water and nutrient uptake. The remaining exodermis is then sustained by the heavily lignified sclerenchyma layer. This layer could function to limit oxygen and gas diffusion from the root to limit anoxic stress, an anatomical adaptation shared by many aquatic plants.

In contrast to the other ground tissues, the mesodermis is composed of four to five cell layers in the radicle, which will differentiate into a lysigenous-schizogenous aerenchyma with intercellular spaces that develop into large lacunae. First, during mesodermis differentiation, the cells become round and spaces between cells are generated. These intercellular spaces are called schizogenous spaces. Later, programmed cell death of mesodermal cells produces cellular spaces called lysigenous spaces. Lysogeny results in a typical radial morphology that includes strands of surviving cortical cells separated by gas spaces [23]. Aerenchyma is regarded as a tissue that is devoted to gas exchange from the shoot and acts as a reservoir of oxygen that is required for root respiration under flooding conditions. Development of the aerenchyma is observed in several aquatic plants species and can also be induced by submergence or anoxia in maize [87]. In comparison, aerenchyma formation is constitutive in rice, and cell death is assumed to represent a part of the developmental process. The aerenchyma is visible in all rice root types, excluding the small lateral roots that possess no mesodermis layer. Finally, the innermost cell 
Fig. 2 Shoot unit and root shoot synchronism. a Definition of a shoot unit. The shoot unit (phytomer) is made up of a tiller bud, a leaf, and a node. Note the position of the upper and lower roots. b Schematic view of internal stem structure and the position of the embryonic roots. $C=$ coleoptilar phytomer. c Synchronized emergence of leaves and crown roots. Arbitrary numbers were given to successive internodes of the stem.

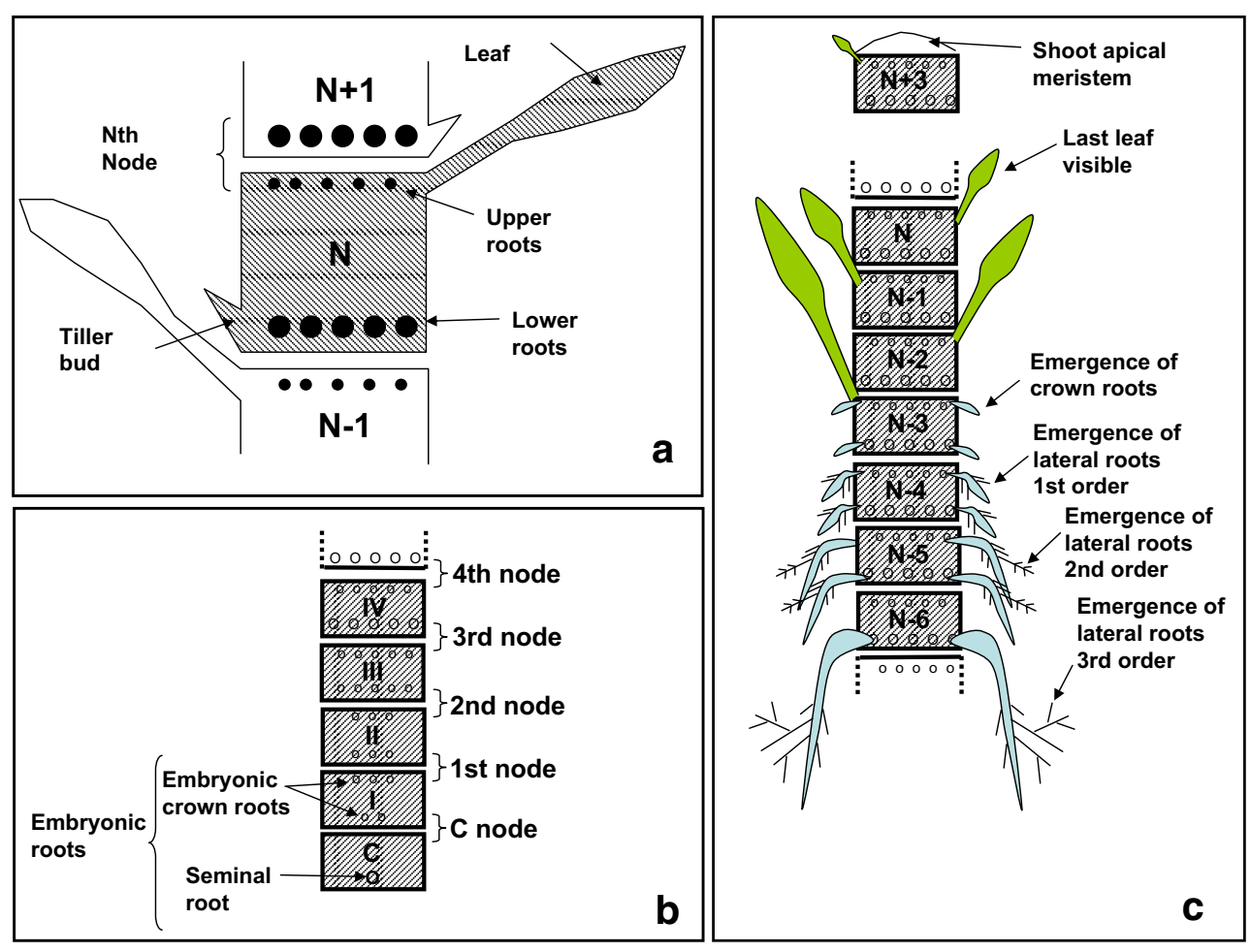

layer of the ground tissue system is the endodermis. Endodermal cells contain the Casparian strip, which is made of suberin and surrounds the entire cell. The Casparian strip was more developed when the roots were grown in soil but remained poorly developed when the roots were fostered under hydroponic conditions. Endodermal cells represent a resistant apoplastic barrier to water and nutrition flow and are known to ensure selective transfer through cell symplasts between the mesodermis and the central cylinder (Fig. 3b).

The organization of the central cylinder organization, with a polyarch structure containing several xylem vessels alternating with phloem, is typical of monocotyledons (Fig. 3b). Xylem forms ridges with the youngest vessels, designated protoxylem, crossing the pericycle. The differentiation of xylem and phloem is centripetal. In the radicle, one or two large central metaxylem vessels are found in the middle of the stele, surrounded by six to eight smaller metaxylem vessels. In these roots, six to seven phloem sieve tube members alternate with the xylem vessels. The phloem is composed of several cell types organized similarly to that of each protophloem sieve tube member, which is associated with two companion cells, and the metaphloem sieve element formed a characteristic symmetrical pattern (Fig. 3c). The space between the xylem and phloem is filled with sclerenchyma fibers (Fig. 3b), and the pericycle represents the external cell layer of the central cylinder. Figure $3 \mathrm{~d}$ summarizes the typical radial anatomy of the rice radicle root.
The four rice root types display closely related, but distinct, radial anatomies

The morphology of the other rice root types is quite similar to that of the radicle, although various sizes are observed (Fig. 4). The diameter of a mature crown $\operatorname{root}(\sim 1,700 \mu \mathrm{m})$ is twice that of the radicle $(\sim 800 \mu \mathrm{m})$. The diameters of the large and small lateral roots are $\sim 370$ and $\sim 160 \mu \mathrm{m}$, respectively; therefore, a tenfold ratio is observed between crown and small lateral roots. The observed variation in crown root diameter depends on the position of emergence along the stem. The diameter of crown roots tends to become larger during formation of phytomers, until a maximum is reached at the tenth phytomer; they then become smaller [50]. The values obtained herein are illustrative of root diameter variations observed in $\mathrm{cv}$ Nipponbare. An examination of transverse sections of the radicle (Fig. 4a), a crown root (Fig. 4), a large lateral root (Fig. 4c), and a small lateral root (Fig. 4d) using autofluorescence of root cell walls under UV illumination allowed for comparison of radial organization. The four rice root types exhibit clear distinctions between the three parts: the epidermal tissue, the ground tissues, and the central cylinder. Although the radial anatomy of the crown roots (Fig. 4b) and large lateral roots (Fig. 4c) is very similar to that of the radicle, small lateral roots exhibit a much simpler internal structure. The main difference is observed in the contribution of the mesodermis aerenchyma cell layer number to root width, which ranges from three in a large 
Fig. 3 Radial anatomy of a radicle. (A) Transverse section of a radicle, $\sim 2 \mathrm{~cm}$ from the root tip, stained with formaldehyde safranin glycerin acetic acid. Lignins are stained in red, while celluloses are stained in blue. Beneath epidermis, exodermis is the outer layer that protects old root when the epidermis collapses; the exodermis plays epidermis-like function and is sustained by the heavily lignified sclerenchyma layer. Aerenchyma is regarded as a tissue that is devoted to gas exchange from shoot and represents a specific adaptation to flooding conditions. (B) Enlargement of the root stele. Note the typical polyarch structure of the stele with alternance of xylem and phloem $(C)$ Detail of the phloem vessels. Note the characteristic symmetrical pattern of phloem. (D) A schematic representation of radicle transverse organization. Cell types are color-coded, as defined in the figure. $e p$, epidermis; ex, exodermis; $s c$, sclerenchyma layer; me, mesodermis; $a e$, aerenchyma lacunae; en, endodermis; pe, pericycle; $m x$, metaxylem; cmx, central metaxylem; $p p$, protophloem; $c c$, companion cells; $m p$, metaphloem; $p c$, endodermis passage cell; $p x$, protoxylem; $p h$, phloem. Scale bars $(A) 50 \mu \mathrm{m},(B)$ $25 \mu \mathrm{m},(C) 5 \mu \mathrm{m},(D) 50 \mu \mathrm{m}$.
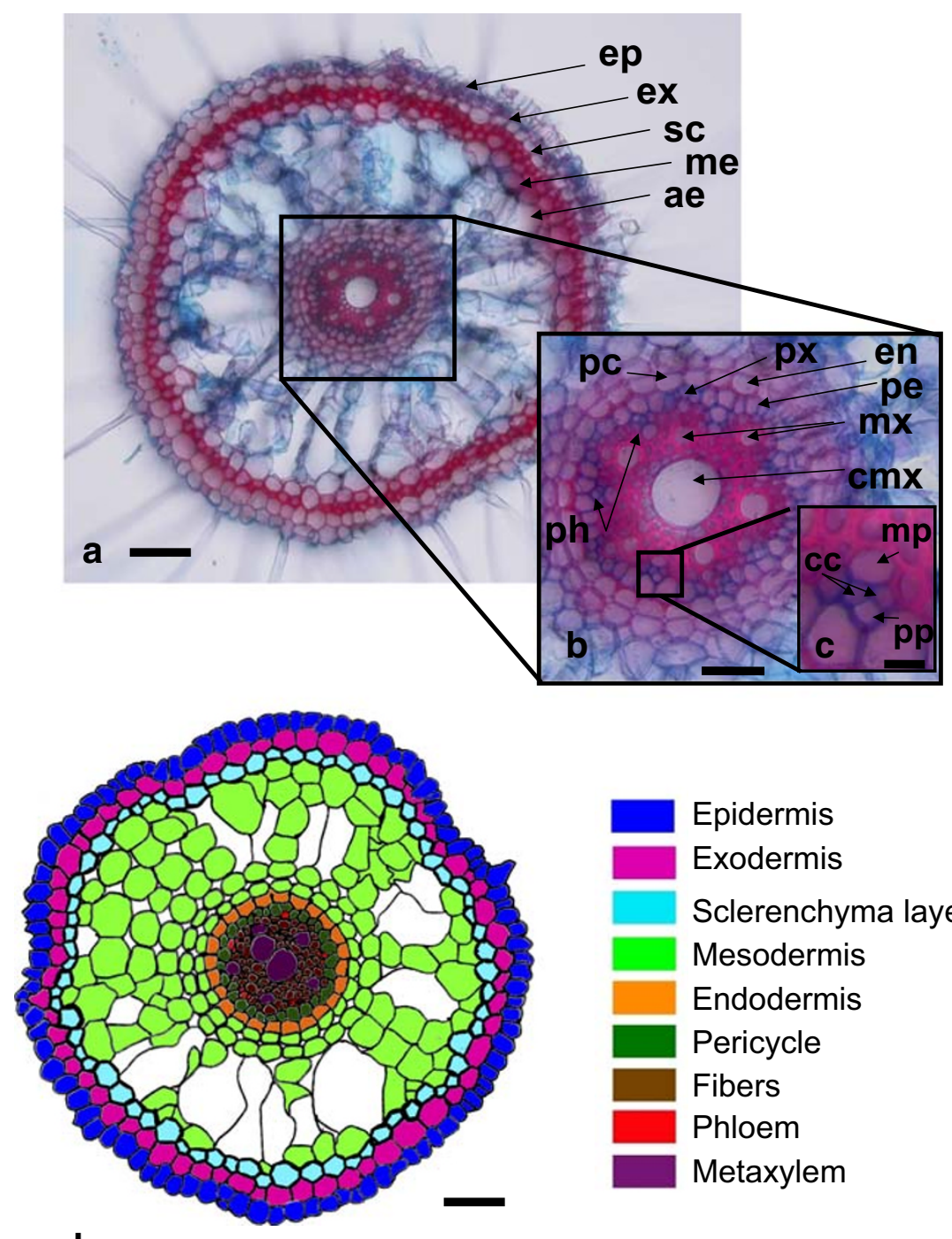

Epidermis

Exodermis

Sclerenchyma layer

Mesodermis

Endodermis

Pericycle

Fibers

Phloem

Metaxylem

d

lateral root (Fig. 4c) to five in the radicle (Fig. 4a) and ten in a mature crown root (Fig. 4b). Small lateral roots demonstrate no cell layer between the endodermis and the sclerenchyma; they also have no aerenchyma (Fig. 4d). The polyarch structure of the stele is also visible in all root types, with one or two large central metaxylem vessels present in the large lateral roots (Fig. 4c) and four to five vessels in the crown roots (Fig. 4b). The central metaxylem vessels are surrounded by nine to 12 metaxylem vessels in crown roots and four to five metaxylem vessels in large lateral roots. Small lateral roots do not have a central metaxylem vessel; rather, they possess two to three metaxylem vessels. The number of phloem sieve tube members range from two in small lateral roots to four in large lateral roots and to six to seven in the radicle and ten to 11 in crown roots. If the same central cylinder organization was shared between the radicle, crown roots, and large lateral roots, the number of cell layers in the stele would increase from small to large roots. Large lateral roots belong to two different types, $\mathrm{L}$ and $\mathrm{T}$, based on [60]; the only difference between them is that the sclerenchyma layer is missing in T-type roots.

The root-hair differentiation pattern in rice is typical of monocot species

Root hairs differentiate from epidermal cells, and their patterning has been extensively studied in A. thaliana, which exhibits a distinct position-dependent pattern of roothair cells and nonhair cells [29]. Root-hair cells (trichoblasts) are present outside the intercellular space between underlying cortical cells, whereas nonhair (atrichoblasts) cells can be found adjacent to cortical cells. This radial pattern is clearly absent in rice, in which all epidermal cell files bear root hairs. However, within each epidermal cell file, a root-hair epidermal cell (the shorter cell) is always 
Fig. 4 Comparative radial anatomy of a radicle, crown root, and large lateral and small lateral root. (A) Radicle transverse section, $\sim 1.5 \mathrm{~cm}$ from the root tip. (B) Crown root transverse section, $\sim 6 \mathrm{~cm}$ from the root tip. (C) Large lateral root transverse section $\sim 2 \mathrm{~cm}$ from the root tip. (D) Small lateral root transverse section. All rice root types display closely related radial anatomies but with variations of the number of mesodermal cell layers. Pictures are not at the same scale. ep, epidermis; ex, exodermis; $s c$, sclerenchyma; me, mesodermis; ae, aerenchyma; en, endodermis; $p e$, pericycle. Scale bars, $50 \mu \mathrm{m}$. All observations were made under UV illumination. Crown and large lateral roots were collected from 40-day-old plants, while radicles and small lateral roots were collected from 1-week-old seedlings.

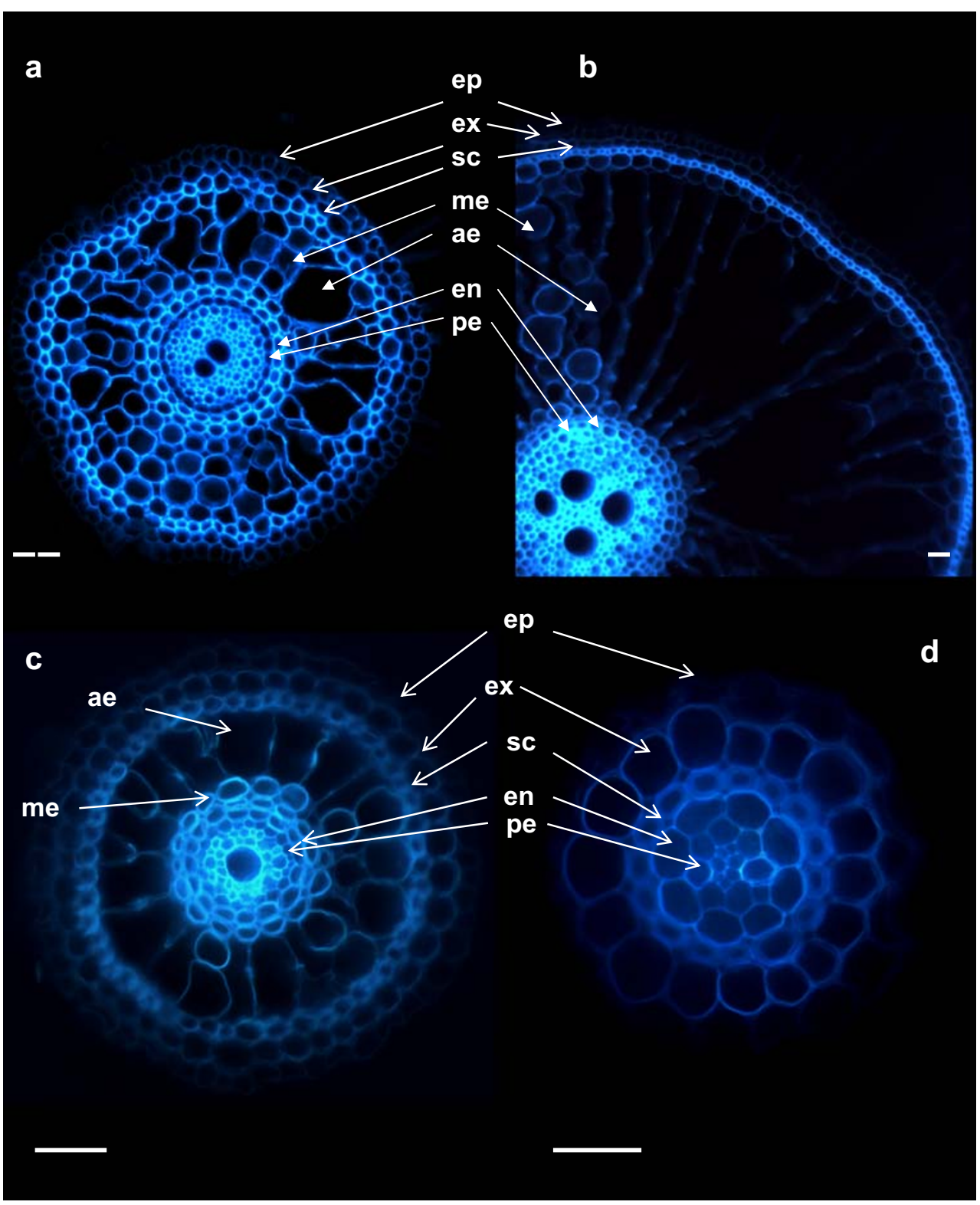

adjacent to a non-root-hair cell (the longer cell), suggesting that the root-hair epidermal cell appears after the single cell division that generates the root-hair cell and non-root-hair cell [51]. The $A$. thaliana root-hair patterning type is shared by all species of the Brassicae genus [29], whereas the rice pattern (i.e., a short cell bearing a root hair alternating on the same file with a long, non-root-hair cell) is typical of monocotyledonous plants [9], as well as ferns and basal angiosperms [59]. Recent results have demonstrated that downstream cis-regulatory modules for root-hair-specific gene expression are conserved across angiosperms, despite divergence of upstream fate-determining machinery. These divergent processes are responsible for the distinctive roothair patterning observed in the root epidermis [59]. Asymmetric division gives rise to the alternating short and long cells present in epidermal cell files. The distal daughter of the initiating mitosis becomes the trichoblast in Poacees (including rice), Juncaceae, Restionaceae, and Cyperaceae, although this role is played by the proximal daughter cell among most other monocots, generating a vertical pattern [10]. When the function of root hairs declines, they are shed from the root together with the epidermal cells. The exodermis then becomes lignified, so as to maintain the root structure along with the sclerenchyma cell layer.

A root-hairless rice mutant, root hairless 2 (rh2), was identified during a screen of $60,000 \mathrm{M} 2$ seedling following treatment with $10^{-3} \mathrm{M} \mathrm{NaN}_{3}$ [88]. Besides the complete absence of root hairs, there was also a strong reduction in root length among all root types, as well as a strong reduction in plant height. Nevertheless, the mutation does not affect the number of crown roots or the morphology of 
leaves. In order to determine whether the phenotype of rh2 was due to an epidermal defect, Suzuki et al. performed histological analyses of the root epidermal cells in $r h 2$. The epidermal cell length of $r h 2$ atrichoblast cells did not differ from that of control cells, suggesting that the mutation specifically affects root-hair formation [88]. Indeed, rh2 exhibits only atrichoblasts that display a similar cell length to control atrichoblasts. The trichoblasts in the control lines are always shorter than atrichoblasts, suggesting that the epidermal cell division that produces trichoblasts is missing in $r h 2$ and that only atrichoblasts are present. $r h 2$ was also resistant to 2,4-dichlorophenoxyacetic acid (2,4-D) and naphthalene acetic acid (NAA). Both induced production of root hairs in $r h 2$ that were shorter than those observed in the control lines. The gene corresponding to the mutation has not yet been identified. In A. thaliana, numerous genes involved in root-hair development have been identified [29]. Based on a comparison between the rh2 phenotype and root-hair mutants identified in A. thaliana, TRANSPARENT TESTA GLABRA (TTG) [28], GLABRA 2 (GL2) [68], and WEREWOLF (WER) [62] genes are good candidates for $R H 2$ because all epidermal cells differentiate into root hairs in the corresponding mutant lines. Alternatively, $R H 2$ could represent a novel component of root-hair development that is missing in A. thaliana as very few truly root-hairless mutants (i.e., without any root hairs) have been identified in $A$. thaliana.

\section{Origin of root types}

The radicle initiates during embryogenesis

and its differentiation is dependant on auxin

Morphological differentiation of the embryo begins 4 days after pollination (DAP) [40]. Three organs are clearly defined at this stage: the coleoptile, the shoot apical meristem, and the root apical meristem (RAM). Most of the morphogenic events are completed at $10 \mathrm{DAP}$; at 20 DAP, the rice embryo is dormant [40]. The RAM of the seminal root will then be reactivated during germination.

Three radicleless mutants, radicleless 1 (rall), radicleless 2 (ral2), and radicleless 3 (ral3), were identified among a total of 188 rice embryo mutants [35]. In the ral1 mutant, the basal structures of the embryo, including the mesocotyl and radicle, are missing [80]. Moreover, the mutant develops fewer crown and lateral roots than the wild type. The diameter of rall roots is reduced since the numbers of xylem poles, phloem vessels, and cortical cell layers are reduced, as is the diameter of the metaxylem cells. The rall mutant is also impaired at maturity; rall plants are smaller and possess shorter leaves. The rall mutant is defective in vascular pattern development both during embryogenesis and postembryonically. Using a procambium-specification marker, ORYZA SATIVA HO$M E O B O X \quad 1$ (OsHOX1) fused to a beta-glucuronidase (GUS) reporter gene, Scarpella et al. demonstrated that the vascular patterning defects arise early during procambium differentiation and that the leaf venation pattern is also affected. $O_{S H O X 1}$ is an early marker of provascular differentiation. When the fate of procambial cells is specified, Oshoxl is required to limit the developmental potential of procambial cells [78]. Moreover, rall is also defective in auxin sensation and response. The rall mutation thus reveals a connection between embryo formation, vascular tissue development, and auxin perception-response. Unfortunately, the molecular nature of the $R A L 1$ gene remains unknown.

Crown roots differentiate from the stem by a mechanism involving auxin and LOB transcription factors

In $A$. thaliana, adventitious roots can sporadically emerge from endodermal cells in the stem and from the pericycle in hypocotyls [24, 84]. In rice, the crown root primordia originate from ground meristem cells in the parenchyma adjacent to the peripheral cylinder of the vascular bundles in stems [40]; crown root primordia are established before the emergence of stem leaves [40]. The development of crown roots has been previously described in detail [40]. Briefly, crown root primordia initial cells are produced by periclinal divisions of parenchyma cells (stage $\mathrm{Cr} 1$ ), followed by the establishment of the epidermis-endodermis initial cells, central cylinder cells, and root cap initial cells (stage Cr2). The QHB [47] and ORYZA SATIVA SCARECROW (OsSCR) [46] genes, which are specifically expressed in the QC and endodermis, respectively, are first expressed in the outer layer derived from the first periclinal division ( $\mathrm{Cr} 1)$ of parenchyma cells. Two layers, the epidermis and endodermis, are then established in stage $\mathrm{Cr} 3$ by periclinal divisions of the epidermis-endodermis initial. The endodermal cells then form cortical cells via several periclinal divisions of the endodermis initial (stage Cr4). Expression of $O S S C R$ is downregulated in the daughter cortex cells. The columella is formed by periclinal divisions that occur during stage $\mathrm{Cr} 5$, and the large central metaxylem is also formed at this time. Basic root organization is completed in step $\mathrm{Cr} 5$, at which time all root tissues are visible. Root growth is preceded by the induced cell death of epidermal cells in the node external to the tip of the root primordium $[70,86]$.

crown rootless 1 (crll) and crown rootless 2 (crl2) were isolated from $\mathrm{MNU}$ and $\gamma$-ray M2 mutant populations screens, respectively, in rice [37]. crll is specifically impaired in crown root initiation, while $\mathrm{crl} 2$ is impaired in the initiation and subsequent elongation of crown roots. 
Furthermore, crl2 shows many additional abnormal morphological characteristics [37]. adventitious rootless 1 (arll) was isolated as a tissue culture-derived rice mutant defective in adventitious root formation [67]. arl1 and crl2 are partially sterile, while $\mathrm{crll}$ grows almost normally and produces normal panicles. CRL1 and CRL2 are not allelic, and crown root initiation can be partially rescued only in crl1 following treatment with $10 \mu \mathrm{M} \alpha$-NAA; this confirms that crll and crl2 mutations correspond to two different genes [37]. In contrast, CRL1 and ARL1 are allelic and have been isolated from two cultivars by positional cloning [39, 67]. CRL1 encodes a lateral organ boundary (LOB) family transcription factor, the expression of which is regulated by auxin through an auxin response factor (ARF). The plant-specific LOB/AS2 family contains 43 members in $A$. thaliana and 35 members in rice [83]. crll and arll mutants develop a normal radicle but form no crown root primordium, indicating that $C R L 1 / A R L 1$ is a master gene for crown root primordium formation. In both mutants, several additional auxin-related phenotypic traits are visible, including a decrease in lateral root number, auxin insensitivity in lateral root formation, and impaired root gravitropism. GUS expression analyses using the auxin maximum reporter DR5::GUS indicate that CRL1 expression colocalizes with the maximum expression level of auxin in the roots and stem [39]. In conclusion, the CRL1 protein is a positive regulator of crown root and lateral root formation, and its expression is regulated by an ARF via the auxin pathway. Interestingly, in A. thaliana, several studies have shown that adventitious and lateral root formation is under auxin control [3]. However, the argonaute 1 (agol) mutant forms a minimal number of adventitious roots, but agol roots are able to form normal lateral roots. These data support the hypothesis that different regulatory pathways control lateral root and crown root formation not only in cereals [34] but also in dicotyledons. Functional analysis of $A R F 17$ demonstrated that this gene is a major regulator of adventitious root development in A. thaliana [84]. Several ARFs regulate the expression of LOB genes involved in lateral root formation [72]. Indeed, the expression of $L B D 16, L D B 29$, $L B D 17$, and $L B D 18$ [72] is reduced in arf7/arf19 single or double mutants. In $A$. thaliana, $L B D 16$ seems to be involved in lateral root formation [61]. $L B D 16, L D B 29$, $L B D 17$, and $L B D 18$ genes are the closest homologs of the $A R L 1 / C R L 1$ gene in rice based on phylogenetic analyses of the LOB family. Taken together, these results suggest that similar pathways for adventitious formation may exist in rice and $A$. thaliana despite differences in the cellular origin. Moreover, there exists partially overlapping genetic networks shared during lateral and adventitious root formation.
Lateral roots originate from pericycle and endodermis cells, and their differentiation is regulated by auxin

Lateral roots in rice arise from anticlinal symmetrical divisions in the pericycle and endodermal cells located opposite to the protophloem and between two protoxylem poles. Lateral root cap cells originate from the endodermis, while epidermis, ground tissues, columella, and stele originate from the pericycle [54]. The first lateral root primordia are visible $\sim 1.5 \mathrm{~mm}$ from the root tip. Longitudinal sections of the radicles of rice seedlings were stained and observed to evaluate early steps of small lateral root development. Figure 5a shows the earliest evidence of lateral root initiation, which precedes several periclinal and anticlinal divisions (Fig. 5b,c) leading to root emergence via breakage of all the tissues (Fig. 5d). Lateral root initiation occurs opposite to the protophloem (Fig. 5c-e). The connection between the vascular system of a small lateral root and the radicle is shown in Fig. 5e. Lateral root primordia are derived from at least two cells from the pericycle and two cells from the endodermis (Fig. 5a). Several anticlinal divisions occur in both layers, increasing the number of cells in the small lateral root primordium (Fig. 5b). In small lateral roots, the root cap originates from endodermal cells, while the epidermis, ground, and stele tissues are derived from the pericycle (Fig. 5c). At later stages, the number of layers in the small lateral root primordium increases by successive periclinal divisions in the pericycle-derived layer (Fig. 5d). In Fig. 5d, the root primordium is almost ready to emerge from the primary root. A more detailed description of the formation of the lateral can be found in [54]. Indeed, it seems that some of the lateral root primordial cells originating from the endodermis generate a "tasche," a temporary structure that is later replaced by a new root cap, although some cells of endodermal origin will form the lateral root epidermis. The primary root cap of crown roots is a temporary structure in rice [58] and is replaced a few days later by a root cap that originates from the pericycle cells. These results suggest that a similar process also exists concerning the lateral root cap origin. A more detailed analysis, similar to that of [21], is therefore required to better understand lateral root formation in rice and to clarify whether the endodermal origin of the root cap is a temporary structure that is later replaced by cells of pericycle origin. Two kinds of lateral roots can originate from primary roots: the large lateral roots and the small lateral roots. The development of their corresponding primordia is similar, except that, at a very early stage, additional periclinal cell divisions in the endodermal cell layer produce additional mesodermis cell layers in the large lateral roots [54].

A mutant named Lateral rootless 1 (Lrt1/Rm109) that is resistant to 2,4-D was isolated after screening a large 
Fig. 5 Small lateral root origin. a First anticlinal cell division visible in the pericycle and endodermis. b A later stage in which two additional anticlinal divisions of the inner cell layer are visible. $\mathbf{c}$ Periclinal divisions inside the lateral root primordium giving rise to two inner cell layers. d At the later stage, almost all of the future lateral root cell layers are visible: the lateral root is ready to emerge. a-d Longitudinal sections of a radicle stained with naphthol blue black. e Transverse section of a radicle root through a lateral root showing the vascular connection between the primary root and the lateral root (illuminated under UV). en, endodermis; $p e$, pericycle; $r c$, future root cap; ep, epidermis. Scale bars (a-e) $25 \mu \mathrm{m}$.
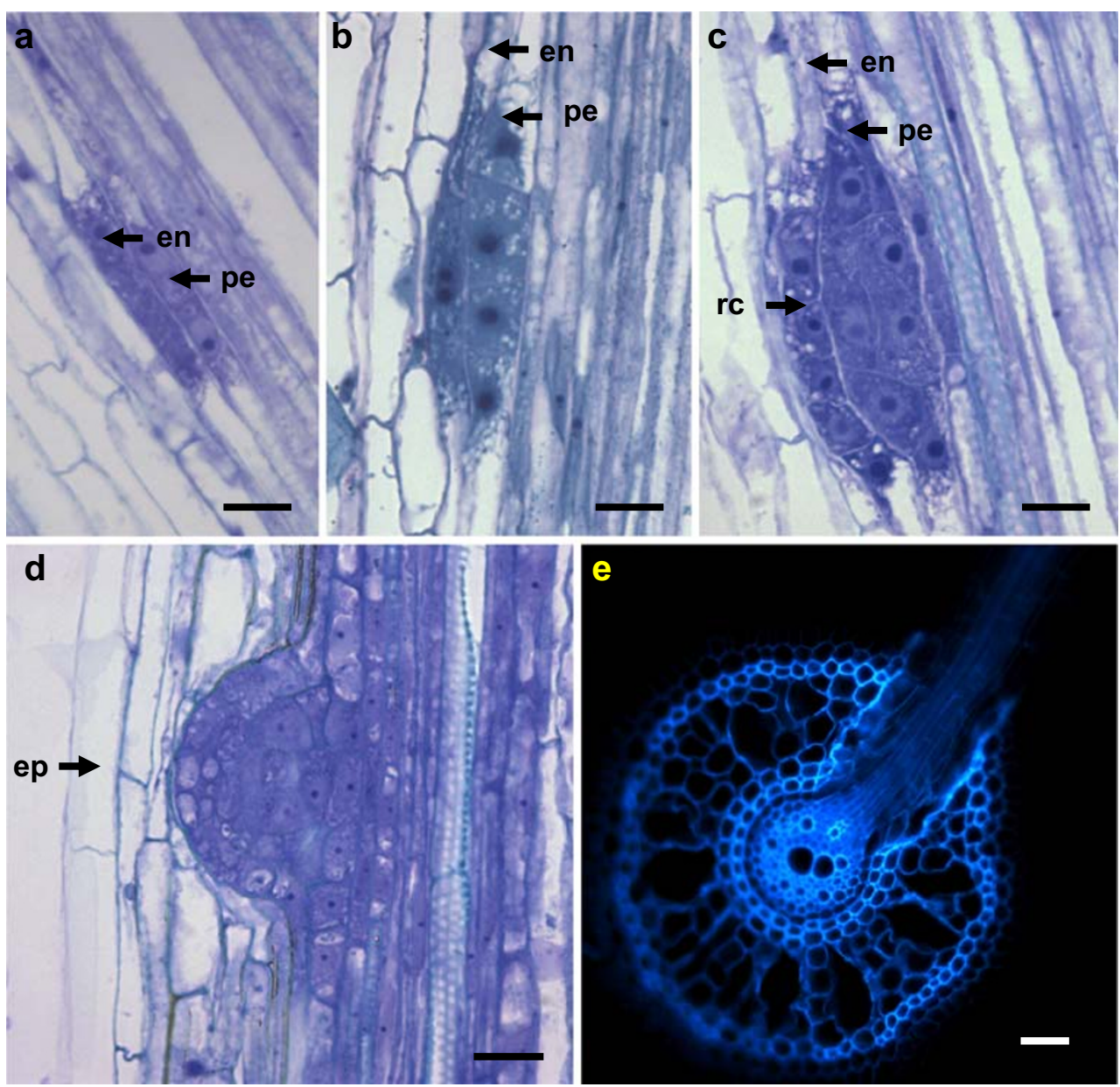

population of $\mathrm{M} 2$ seeds treated with $\mathrm{NaN}_{3}[6,31]$. Lrt1 has a specific phenotype: it lacks lateral roots and also demonstrates altered gravitropism and root-hair formation. The mutation is dominant, suggesting that it is a gain of function. No significant differences were observed between Lrt1 and the control line regarding plant height, the number of crown roots, or seminal root length. Lrt1 is also resistant to indole3-butyric acid, a natural auxin that was identified in monocots. While the molecular function of the gene is unknown, Lrt1 is similar in appearance to the Solitary-root/ iaa14 (Slr1) mutation described in A. thaliana [26], as the mutation is dominant and the phenotype described for $A$. thaliana is very similar to that observed for rice. The Slr1 mutant completely lacks lateral roots and is defective in roothair formation and the gravitropic response of the root. Moreover, Slr1 is also resistant to auxin, and formation of lateral roots can be only slightly induced by auxin [26]. The Slr-1 mutation blocks early cell divisions in the lateral roots. SLR1 encodes IAA14, a member of the auxin-indole acetic acid (Aux/IAA) protein family; the mutation corresponds to a single amino acid substitution in the second of four highly conserved domains. IAA14 represses auxin-induced gene expression and acts as a transcriptional repressor. Aux/IAA repressors function in combination with the ARF transcrip- tion factor and dimerize in an auxin-regulated manner. The Slr 1 mutation affects the degradation of IAA14 in response to auxin. For this reason, Slr1 constitutively inactivates ARF7 and ARF19 functions, thereby blocking lateral root initiation [26]. In rice, initiation of crown roots is normal in the Lrt1 mutant [6, 31], suggesting that the dominant Lrt1 mutation affects only lateral root development and that lateral and crown root formation can be genetically resolved. Positional cloning of Lrt1 will allow for a better understanding of lateral root developmental mechanisms in rice and will aid in unraveling the genetic pathways responsible for lateral and crown root formation.

\section{RAM structure and initials of Oryza sativa roots}

\section{RAM structure}

\section{Closed meristem, cell convergence, and the distinction between structural and functional initials}

In rice roots, all tissues originate from the RAM, which is composed of three histogens, a calyptrogen (root cap), a dermatogen-periblem complex (all tissues from epidermis 
to endodermis), and plerome (stele tissues) surrounding a putative quiescent center (QC; Fig. 6a,b).

In $A$. thaliana, the small cells surrounding the $\mathrm{QC}$ are defined as the initials [81]. It is tempting to define the small groups of cells at the convergence point as root initials in rice by reference to $A$. thaliana, but the size of the QC was shown to be much larger in Poaceae and in most of plants with larger roots than those of $A$. thaliana [8]. In maize, the meristem is large, and most of the cell divisions directly abut the QC [43], suggesting that the small group of initials in the lineage convergence region is not the principal source of most of the new root cells. Barlow [1] considered the QC to be part of a founder zone containing cells possessing variable amounts of "stemness." Barlow defined two types of initials cells: functional and structural cells. The former type divides frequently, directly abuts the QC surface, and represents the source of most new root tissue derivatives; the latter type divides infrequently and is involved in the replacement and addition of new functional initials. These structural and functional initial cells are also active during embryogenesis, or soon after germination, in setting up the root cell layers, and in RAM structure. In this respect, the stem cells of $A$. thaliana, like the endodermis-cortical initials, are structural initials. Indeed, the $A$. thaliana stem cells divide much less frequently than the surrounding cells [4, 19], and most endodermis-cortical initial divisions are observed a few days after germination, whereas the cortical layer, an outer cell layer, is established 1 week later [2, 73]. Three weeks later, a middle cortex cell layer is produced via additional periclinal cell divisions in the endodermis distal to the endodermis-cortical initial $[2,73]$.

\section{$Q C$ and putative structural initials in rice}

Rice RAM belongs to the closed meristem type, with structural initial layers arranged in three tiers. The first tier, made up of the peripheral root cap and columella initial cells, produces the root cap and columella. The second tier is made up of epidermis-endodermis initial cells. Finally, the last tier is made up of stele initial cells. The RAM structure of the rice radicle appears to be very similar to that of maize [42]. The maize RAM QC is very large [42, 43] and contains $800-1,000$ cells $[42,43]$. There is, to our knowledge, no information on the QC size in rice based on classical techniques, such as ${ }^{3} \mathrm{H}$ or BrdU incorporation. Some recent molecular analyses suggest that the QC is rather small in rice. $Q H B$ is the ortholog of WUSCHEL RELATED HOMEOBOX 5 (WOX5), which is specifically expressed in the QC of $A$. thaliana [30]. $Q H B$ is also specifically expressed in three to four cells of the rice RAM [47], and $O s S C R$ overlaps with $Q H B$ expression in these four cells, as it does in A. thaliana, suggesting that these cells define the QC. This pattern of expression tentatively suggests that the rice QC is very small. Nevertheless, no additional experiments support this view. For instance, Umeda et al. [89] analyzed the expression of four CDK genes (CDS2OS1, CDC2OS2, CDC2OS3, and R2) by in situ hybridization in rice roots. CDS2OS1 and CDC2OS2 were expressed throughout the cell cycle, and analysis of their expression in the RAM revealed a large region at the root tip extremity with almost no expression of these two genes, suggesting that a broad QC exists in rice [89]. Moreover, Clowes [8] demonstrated that Poaceae roots have a large QC. This apparent contradiction can be resolved if we imagine that the $\mathrm{QC}$ extends beyond $Q H B$ expression. For instance, the root expression of the ZmSCR ortholog is similar in maize to that described for $A$. thaliana. It is found only in a single cell layer and extends inside the QC [66], suggesting that, in Poaceae, the overlapping expression of $A$. thaliana $W O X 5$ and $S C R$ orthologs does not define the QC. Moreover, since there is clearly a correlation between QC size and RAM size in
Fig. 6 Median longitudinal view of a radicle root tip deduced from anatomical observations. a Cell types are colorcoded according to Fig. 3. b Schematic drawing of cellular patterns and cell files in RAM. The tissues of cap, stele, and epidermis-endodermis are discrete and converge inside the RAM.

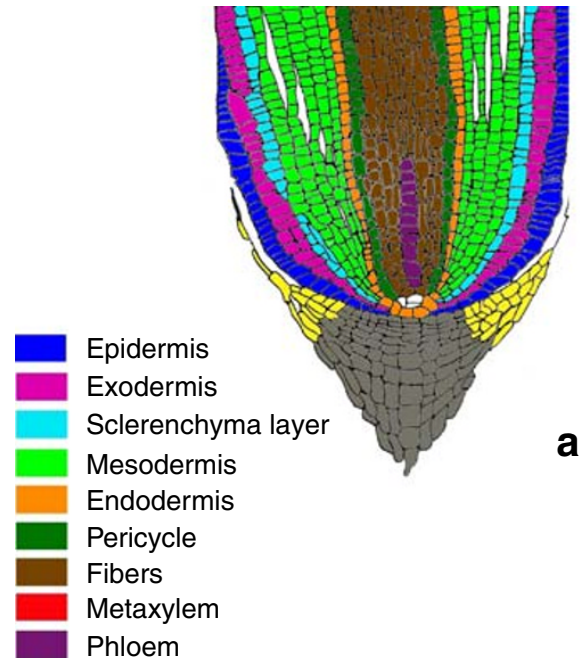

b 
plants [8], the QC size in the RAMs of the four rice root types and in crown roots of different diameters probably differs. Additional studies, including mitotic index and BrdU studies, are needed before any definitive conclusion can be made regarding the RAM QC size in rice.

Transformants harboring a QHB-promoter-GUS fusion and in situ hybridization demonstrate that $Q H B$ is specifically expressed in the central cells of the QC in the root [47]. Different patterns of $Q H B$ expression are found between the radicle and crown roots, suggesting differences in their developmental mechanisms. None of the transformants expressing antisense or RNA interference targeting $Q H B$ displayed a phenotype. Among overexpressing lines, the ten plants with the most severe phenotypes did not develop any crown roots, but the radicles and lateral roots appeared normal. The severity of the phenotype was correlated with the level of $Q H B$ expression. Rice plants overexpressing the $A$. thaliana $W U S$ gene display a similar phenotype to that of $Q H B$-overexpressing lines, including dwarfism and multiple shoots with malformed leaves [47]. This last result suggests that a significant part of the phenotype observed in $Q H B$-overexpressing plants is related to the expression of $Q H B$ in all tissues but is not directly related to normal $Q H B$ function. Hence, it is difficult to come to any conclusion regarding the precise function of $Q H B$ in rice. $Q H B$ is the ortholog of two $A$. thaliana genes, WUSCHEL RELATED HOMEOBOX 7 (AtWOX7) and AtWOX5. While there are no data available concerning the function or expression pattern of $A t W O X 7$ in A. thaliana, a recent paper demonstrated that AtWOX5 is specifically expressed in the RAM QC and that a loss of function in AtWOX5 causes terminal differentiation in the distal stem cells, the columella initials [76]. Moreover, the activity of AtWOX5 is redundant, provoking the differentiation of proximal meristems, including procambium and cortical-endodermal initials, together with another regulator [76]. AtWOX7 might be a candidate for this redundant regulator; however, its function remains unknown.

A short root rice mutant was isolated by screening a TDNA insertion library [64]. The mutant is defective in root elongation in all root types during the first 2 weeks after germination. After 2 weeks, the length of newly emergent roots is normal relative to the wild type, suggesting that this mutation specifically affects early root growth. Using thermal asymmetric interlaced polymerase chain reaction, the authors identified the site of the T-DNA insertion responsible for the mutant phenotype. The T-DNA was found to be inserted in the first intron of the 5'-untranslated region of a glutamate-receptor-like gene called GLR3.1 [64]. Complementation of the mutation was achieved using a 7.6-kb genomic DNA fragment containing the promoter and coding region of GLR3.1. GLR3.1 is expressed at a low level in roots and shoots and GLR3.1 could form homomultimeric complexes, a common feature of animal glutamate receptors. More interestingly, GLR3.1 was found to be critical for the mitotic activity of the RAM. Using BrdU incorporation as a marker of mitotic activity in RAM, the authors demonstrate that the mutant displayed a lower level of BrdU at the QC site compared to the control. Moreover, BrdU incorporation was detected in the lateral root cap initial cells only in the mutant line. The enhanced mitotic activity in the RAM of the mutant is linked to premature cell differentiation. Altogether, these results highlight the fact that the reduced QC size in the mutant induces a decrease in cell division and premature cell differentiation in the rice RAM. Additional cell layers are found in the lateral root cap of the mutant [64], confirming this hypothesis. In animals, Glu receptors may be involved in neuronal cell death [13]. In the glr3.1 mutant, excessive programmed cell death, as detected by the terminal transferase uridyl nick end labeling assay, was observed throughout the RAM. In contrast, in the control line, programmed cell death was restricted mainly to the lateral root cap. In conclusion, GLR3.1 seems to be involved in root development in rice and to act as a regulator of cell death and cell proliferation. The function of glutamate receptors remains obscure in plants; however, several recent publications suggest that L-glutamate acts as a specific exogenous signal to modulate root growth and branching $[17,90]$. Furthermore, L-glutamate activity is not related to its action in amino acid metabolism; rather, it acts specifically as an exogenous signal, and perception of Lglutamate occurs in the root tip [90]. Specifically, $50 \mathrm{mM} \mathrm{L}-$ glutamate inhibits cell division in $A$. thaliana primary roots but not in lateral roots [90]. Together, these results suggest that L-glutamate and Glu receptors modulate RAM mitotic activity in plants.

\section{Peripheral root cap and columella initial cells (calyptrogens)}

The root cap is made up of columella and peripheral root cap cells that arise from a group of initial cells [57]. The columella cells are produced through periclinal divisions of columella initials (Fig. 7, white arrows), whereas peripheral root cap cells are produced via periclinal divisions (Fig. 7b, black arrow), followed by additional rounds of anticlinal divisions. This results in the sloughing off of peripheral root cap cells, which aids in root penetration into the soil. A similar pattern of root cap development is observed in all rice root types (see also below and Fig. 7b). Columella cells differentiate later and contain numerous amyloplasts involved in the gravity response. Therefore, root cap cell production appears to occur totally independent of other tissues. This observation explains why the root cap fully surrounds the meristematic zone. Columella cells derive 


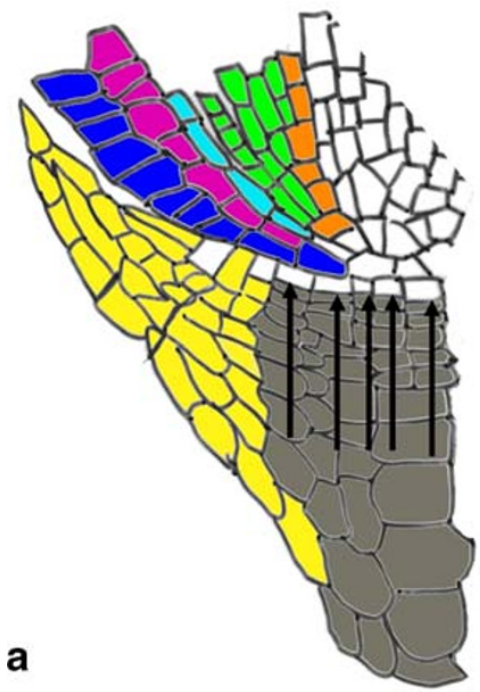

Fig. 7 Cell division pattern of the lateral root cap, columella (a), and epidermal endodermal initial cells (b). a Columella initials are regenerated through a first anticlinal division (black arrows), whereas peripheral root cap cells are formed following a first periclinal division followed by several anticlinal divisions. Cell types are color-coded according to Figs. 3 and 6. b Divisions of the epidermis-endodermis

from the periclinal divisions of a single layer in both $A$. thaliana and rice. However, peripheral root cap cells are produced through the initial periclinal division of a common epidermis-peripheral root cap initial in A. thaliana [19], whereas, in rice, peripheral root cap formation occurs via periclinal divisions of columella root cap initial, followed by anticlinal cell divisions. The cortical origin of rice epidermal cells is a classical feature of monocots, as well as some basal angiosperms [10], while the common origin of the lateral root cap and epidermis in A. thaliana is fairly typical of dicotyledonous roots [10].

\section{Epidermis-endodermis structural initial cells (the dermatogen-periblem complex)}

Just between the columella initials and the stelar pole, a single layer of epidermis-endodermis structural initial cells is visible and represents the origin of the epidermis and all ground cell layers (Fig. 7b). These initials belong to the dermatogen-periblem complex $[52,53]$. The first anticlinal cell division (Fig. 7b, dotted arrow) generates two daughter cells. The first regenerates the initial, and the other generates the endodermis initial, which gives rise to the epidermis and all ground tissues after seven to eight asymmetric periclinal divisions (Fig. 7b, yellow arrows). The first asymmetric periclinal division produces the epidermis and endodermis, based on the cell wall positions. The external epidermal cells repeat their anticlinal divi-

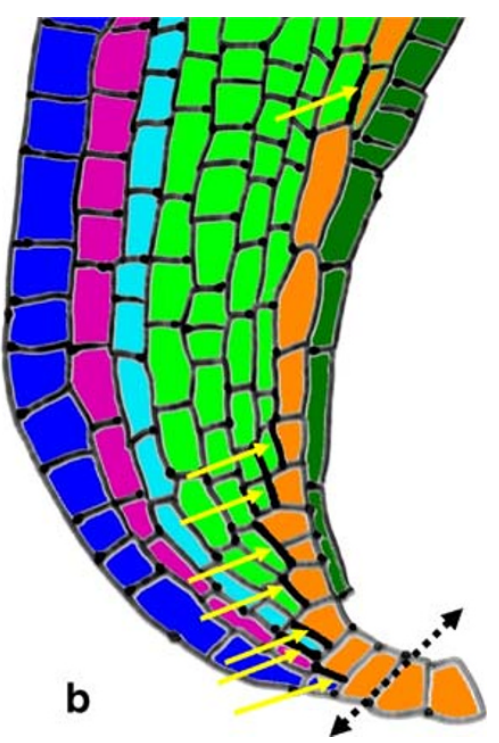

initials. The dotted double arrow describes the first anticlinal division near the QC that regenerates the initial and produces the epidermisendodermis-derived initial. Eight successive asymmetrical periclinal cell divisions (yellow arrows) follow the first anticlinal division and generate, successively, the epidermis-endodermis, sclerenchyma layer, exodermis, and five layers of the cortex.

sions, but without any additional periclinal divisions, to form a cell monolayer. The endodermis undergoes several rounds of asymmetric periclinal divisions to generate, successively, the exodermis, the sclerenchyma, and all of the cortical cell layers (Fig. 7b) [52]. Differences in cortical cell layers between the crown, radicle, and large lateral and small lateral roots can then be easily explained by differences in the number of asymmetric periclinal cell divisions that occur during embryogenesis and/or root primordia formation [53]. Moreover, in small lateral roots, three sequential periclinal divisions likely occur, giving rise to the epidermis, exodermis, sclerenchyma, and endodermis (Fig. 8, yellow arrows) but with no additional mesodermis layer that later differentiates into aerenchyma in all other root types. Thus, the meristem in the lateral root seems to work similarly to that in other root types, and the same pattern of division in initials previously described for the radicle meristem is observed in short lateral roots: periclinal divisions for columella initials (red arrows, Fig. 8), anticlinal divisions for peripheral root cap initials (white arrow, Fig. 8), and periclinal divisions resulting in epidermis to endodermis formation (yellow arrows, Fig. 8). Therefore, seven to eight periclinal divisions of the endodermis initials are observed in the radicle, while up to 15 to 16 can be observed in the crown root, five in the large lateral root, and three in the small lateral root.

$A t S C R$ is involved in the asymmetrical divisions that generate separate endodermal and cortical cell lineages. The 


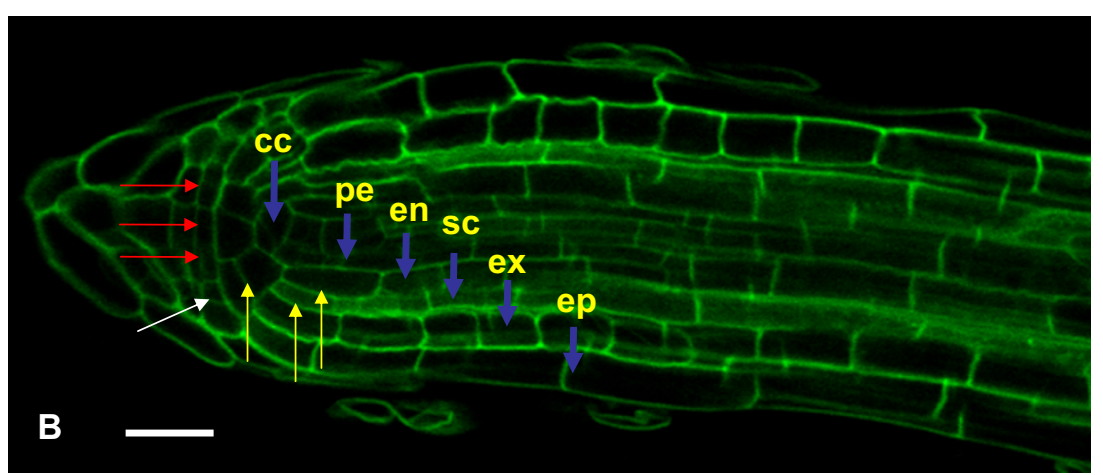

Fig. 8 A median longitudinal view of a small lateral root visualized under UV based on cell wall autofluorescence using a two-photon laser scanning microscope. The same pattern as described for the radicle meristem is observed: periclinal divisions for columella initials (red arrows), anticlinal divisions for peripheral root cap initials (white arrows), and three sequential periclinal divisions occur, giving rise to epidermis, exodermis, sclerenchyma, and endodermis (yellow arrows). $c c$, central cells; en, endodermis; $p e$, pericycle; $s c$, sclerenchyma layer; $e x$, exodermis; $e p$, epidermis. Scale bar $50 \mu \mathrm{m}$. continuous endodermal $O S S C R$ expression in rice correlates well with the function proposed for AtSCR in A. thaliana [18]. SHORT-ROOT (AtSHR) expression occurs only in the stele region, and a recent analysis of $O S S H R$ [14] suggests that $O s S H R$ and AtSHR exhibit similar patterns of expression in rice and $A$. thaliana. In situ hybridization shows that $Q H B$ and $O s S C R$ expression overlap at the position of the putative rice QC in RAM. Hence, these results suggest that the function of $O S S C R$ is probably similar in rice to that described for $A$. thaliana (i.e., it is involved in the periclinal cell division of endodermis-cortex initials and maintenance of a QC stem cell niche). OsSCR is also expressed in the stomata and ligule during asymmetric division, suggesting a broader function of $O S S C R$, not only in roots but also in stomata and ligules. The AtSCR protein blocks the movement of AtSHR by sequestering it in the nucleus. In rice, there are two putative orthologs to either AtSCR (OsSCR1, OsSCR2) or AtSHR (OsSHR1, OsSHR2). AtSCR and AtSHR proteins interact directly in yeast two-hybrid assays. Using this experimental system, Cui et al. [14] demonstrated that OsSCR1 interacts with AtSHR; whereas OsSHR1 interact with AtSCR, suggesting that OsSCR1 and OsSHR1 are probably the rice functional equivalents of AtSCR and AtSHR, respectively. OsSHR2 does not interact with OsSCR1 or AtSCR, while the interactions of OsSCR2 were not evaluated. These results reinforce the idea that at least $O S S H R 1$ and $O S S C R 1$ in rice probably have functions similar to AtSHR and AtSCR, respectively. Nevertheless, the functions of these genes have yet to be determined in planta, and their biological function in rice RAM remains to be elucidated. Recently, a second periclinal division was shown to occur and give rise to a second layer of cortex in aging $A$. thaliana primary roots $[2,73]$. This process seems to be under the control of GA, AtSCR, and AtSHR. Moreover, ectopic AtSHR expression induced formation of several additional endodermal cell layers [32]. It would therefore be interesting to determine if GA and/or variations in $O S S H R$ and $O s S C R$ expression patterns can also affect the number of endodermis periclinal divisions and might be responsible for the observed variation in the number of cortical cell layers in rice root types. Since several GA biosynthesis and perception mutants are available in rice $[22,75]$, this question, as well as the function of $O s S C R$ and $O S S H R$ genes, should be addressed in the near future.

\section{Stele initial cells}

The epidermis-endodermis initials are immediately adjacent by the large cells that close the stelar pole, which, due to their morphology, are called central cells (CCs; Fig. 9a). These CCs have unique morphological features: they are larger than their neighboring cells and can be clearly discriminated from the surrounding meristematic cells (four CCs are visible in Fig. 9 A2). The apparent absence of pericycle cells during this stage suggests that the CCs form the first layer of stele cells. The structural initials surrounding the $\mathrm{CCs}$ undergo anticlinal divisions to regenerate initials and produce daughter cells that will later differentiate into xylem and phloem (Fig. 9).

A reproducible pattern of vessel formation can be deduced via analysis of serial transverse sections of the radicle [71]. The pericycle cells are first observed, followed by the central metaxylem cell appearing just above the CCs after the first anticlinal division of the central metaxylem initial (Fig. 9a). Phloem sieve element formation occurs in three steps. The first visible mother cell is adjacent to two pericycle cells (Fig. 9 B1). An anticlinal division generates the metaphloem cell together with an undifferentiated cell (labeled mp and o, respectively, in Fig. 9 B2,B3). Next, the undifferentiated cell undergoes two successive asymmetrical cell divisions, and the small cells form the companion cells surrounding a single protophloem cell (Fig. 9 B4,B5). 
a

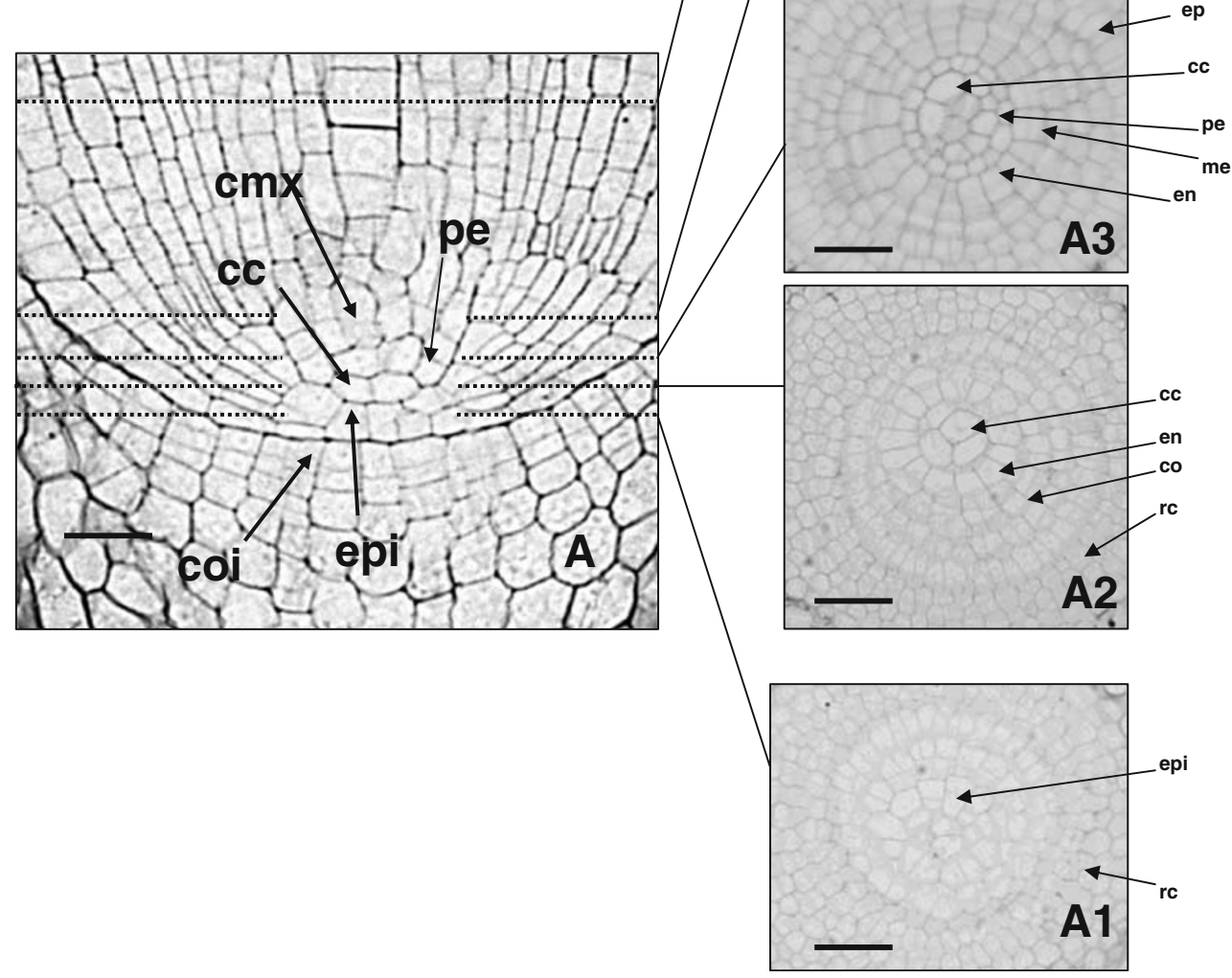

Fig. 9 Stele initial cells $(A)$, serial sections of a single radicle $(A 1-A 5)$, and root vascularization $(B$ and $C)$ : phloem vessel formation $(B 1-B 6)$ and xylem and protoxylem formation $(C 1-C 8)$. (A) Longitudinal view. Dotted lines indicate the approximate position of the transverse serial sections in the RAM. (Al) Transverse section of epidermis-endodermis initials. (A2) Transverse section of large central cells $(C C \mathrm{~s})$. (A3) Transverse section of the first pericycle cells. (A4) Transverse section of the first central metaxylem cell. (A5) Transverse section of the mature stele. Scale bars a $20 \mu \mathrm{m},(A 1-A 5) 25 \mu \mathrm{m}$. (B-C) Root vascularization deduced from anatomical observations $(B 1-B 6)$ Phloem formation. Phloem formation occurs in three steps. An anticlinal division generates the metaphloem cell (B2 and B3); next, the metaphloem sister cells undergoes two successive asymmetrical divisions and the small cells form the companion cells (B4 and B5) surrounding a single protophloem cell. $(\mathrm{Cl}-\mathrm{C} 8)$ xylem and protoxylem formation. Metaxylem originates an initial cell adjacent to two pericycle cells. $(\mathrm{Cl}$ and $\mathrm{C2}$ ). Soon after, several anticlinal and periclinal cell divisions surrounding the metaxylem cell form a single layer of small cells around the metaxylem ( $C 3$ and $C 7$ ). The two pericycle cells adjacent to the metaxylem undergoes several periclinal and anticlinal divisions (C4-C8) after metaxylem formation. These cells will then differentiate later into protoxylem. Dotted lines represent cell divisions. Cells derived from a single initial cell are underlined based on a color code. Blue, phloem; red, metaxylem; green, protoxylem. Scale bars $10 \mu \mathrm{m}$. $r c$, root cap; epi, epidermis-endodermis initial; me, mesodermis; en, endodermis; $c c$, central cells; pe, pericycle; $c m x$, central metaxylem; $e x$, exodermis; $e p$, epidermis; $s c$, sclerenchyma layer; $m x$, metaxylem; $p h$, phloem; $p x$, protoxylem, coi, columella initial, $m p$, metaphloem; $p p$, protophloem; asterisk, initial cell of the phloem vessel; $o$, initial cell for the protophloem and companion cells; $x$ initial cell of the metaxylem vessel; $c o c$, companion cell. 


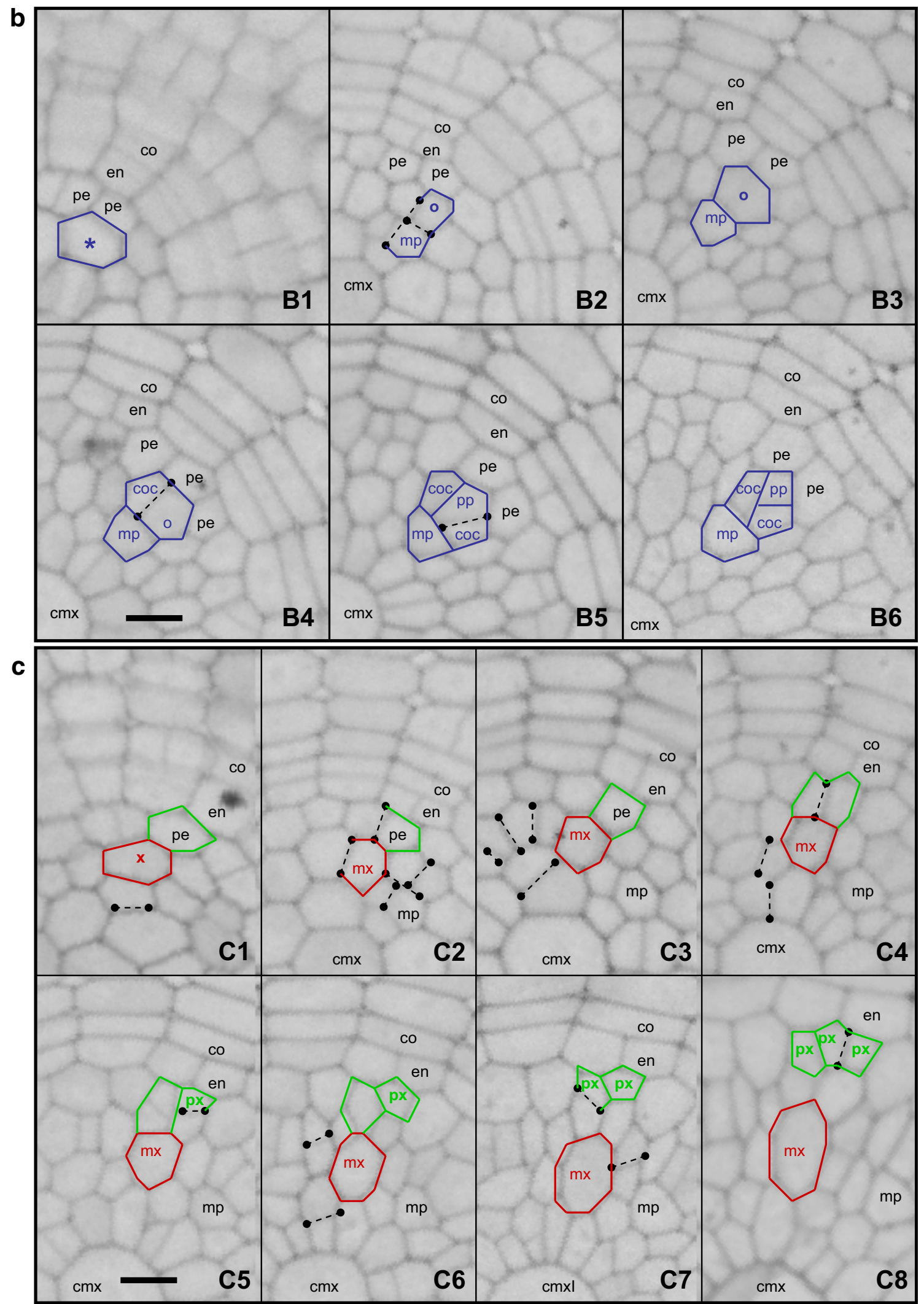

Fig. 9 Continued. 
Note that none of the adjacent pericycle cells seem to divide during phloem sieve element formation. Protophloem differentiates first, followed by differentiation of the metaphloem and its two companion cells (Fig. 9 B5,B6). Metaxylem vessels originate via cell divisions of an initial cell adjacent to two pericycle cells (Fig. 9 C1,C2). Soon after, and concomitantly with metaphloem formation, the development of a set of anticlinal and periclinal divisions surrounding the growing metaxylem vessel (Fig. 9 C3-C7) is visible, forming a single layer of small cells around the xylem vessel (Fig. 9 C8). Just after metaxylem formation (Fig. 9 C3), several periclinal and anticlinal divisions of the adjacent pericycle cells are visible and produce a small set of cells (Fig. 9 C4-C8) that are distinct from the remaining pericycle cells. These cells will then differentiate into protoxylem.

OSHOX1 is a homeodomain leucine zipper (HD-Zip) protein that homodimerizes, but which can also heterodimerize with other HD-Zip proteins [69]. Overexpression of $O S H O X 1$ anticipates the procambial cell fate and induces premature vascular differentiation in the root and shoot [78]. In fact, Oshoxl promotes polar auxin transport capacity and supports procambial cell fate by increasing auxin conductivity and stabilization against variations in polar auxin transport [79].

\section{Future directions}

The study of molecular genetics of rice root development is still in its infancy. The power of this approach in understanding root development is highlighted by the characterization of the crll/arll mutant. This and other mutants affecting root development have paved the way for the identification of genetic networks related to the control of differentiation in all rice root types. This, in turn, will aid in identifying key regulators of root architecture and will generate potential candidate genes for use in breeding programs.

However, the number of available mutants and known genes involved in rice root development remains limited. Molecular identification of root mutants is therefore needed since only two have, as yet, been characterized. In contrast, a total of 18 monogenetic mutants have been isolated in various screens (Table 1). Some of these mutants are probably involved in auxin-related processes, and a very few, including rh2, Lrt1, and ral1, seems to be specifically implicated in root-specific mechanisms. More sophisticated mutant screen procedures are also required, using, for instance, cell-specific marker lines or activation tagging populations to identify new and very specific root patterning genes. Several enhancer trap insertions lines are available in rice and can serve this purpose. For instance, a population of UAS-GAL4-GFP lines was screened, resulting in the isolation of more than 100 lines displaying a cell-specific pattern of expression in roots [45]. These resources will aid in identifying very subtle root cell defects and broader pleiotropic effects on overall plant development.

As described in the "Introduction," numerous QTL analyses have resulted in the mapping of several robust QTLs with effects on root traits, including maximum root length. Isolating these QTLs is a major goal since they will not only identify genes involved in specific root processes but will also reveal functions of genes of agronomical interest. However, this approach is still limited by the high plasticity of the root architecture; therefore, this strategy requires a large population and progeny testing to finely map the QTLs because most, if not all, of these QTLs have only small effects. The combination of fine mapping, candidate gene selection, and mutant studies will greatly accelerate the isolation of root trait QTLs. A common critical feature of all forward genetic approaches is the development of high-throughput phenotyping protocols that efficiently and reproducibly screen several hundred or thousands of plants in order to identify either a few recombinant in QTL fine mapping or a few mutant lines in mutant screening.

Reverse genetics for rice genes orthologous to A. thaliana root genes is also a promising approach. Several powerful tools were recently developed for this purpose, including several T-DNA collections totaling approximately 200,000 independent FST (http://orygenesdb.cirad.fr). Several bioinformatics tools have also been specifically developed for rice reverse genetics [20] and for a genome-wide search of rice$A$. thaliana orthologs $[11,12]$. Systematic functional studies of rice- $A$. thaliana orthologs will not only need to be extended to confirm what is known for $A$. thaliana but also to characterize specific processes that have evolved independently in monocots and dicots. Monocotyledons and dicotyledons have evolved separately over the last 150 million years [5, 93], and a number of morphological and physiological characteristics has become highly specialized in monocotyledons [33]. Even if possible common molecular mechanisms are evident, there is clearly a need for a more complete comparison of the genic repertoires of $A$. thaliana$O$. sativa to formulate and drive hypotheses regarding the molecular origin of anatomical-developmental differences.

The identification of key root developmental genes in rice will help to identify those that explain a significant portion of the natural variation in root traits. This will be crucial for the development of new rice ideotypes that are better armed against environmental challenges. Reciprocally, cloning of root QTLs will also reveal genes that are relevant to root developmental networks. Both approaches will be conducted in parallel over the coming years, and analysis of the results should result in a more refined understanding of the molecular mechanisms of root development in rice and other cereals. 


\section{References}

1. Barlow PW. Structure and function at the root apex - phylogenetic and ontogenetic perspectives on apical cells and quiescent centres. Plant Soil 1994;167:1-16.

2. Baum SF, Dubrovsky JG, Rost TL. Apical organization and maturation of the cortex and vascular cylinder in Arabidopsis thaliana (Brassicaceae) roots. Ann Bot (Lond) 2002;89:908-20.

3. Boerjan W, Cervera MT, Delarue M, Beeckman T, Dewitte W, Bellini C, et al. Superroot, a recessive mutation in Arabidopsis, confers auxin overproduction. Plant Cell 1995;7:1405-19.

4. Campilho A, Garcia B, Toorn HV, Wijk HV, Campilho A, Scheres B. Time-lapse analysis of stem-cell divisions in the Arabidopsis thaliana root meristem. Plant J 2006;48:619-27.

5. Chaw SM, Chang CC, Chen HL, Li WH. Dating the monocotdicot divergence and the origin of core eudicots using whole chloroplast genomes. J Mol Evol 2004;58:424-41.

6. Chhun T, Takeda S, Tsurumi S, Ichii M. The effects of auxin on lateral root initiation and root gravitropism in a lateral rootless mutant Lrt1 of rice (Oryza sativa L.). Plant Growth Regul 2003;39:161-70.

7. Chhun T, Takeda S, Tsurumi S, Ichii M. Interaction between two auxin-resistant mutants and their effects on lateral root formation in rice (Oryza sativa L.). J Exp Bot 2003;54:2701-8.

8. Clowes FAL. Size and activity of quiescent centres of roots. New Phytol 1984;93:13-21.

9. Clowes FAL. Origin of the epidermis in root meristems. New Phytol 1994;127:335-47.

10. Clowes FAL. Pattern of root meristem development in angiosperms. New Phytol 2000;146:83-94.

11. Conte MG, Gaillard S, Droc G, Perin C. Phylogenomics of plant genomes: a methodology for genome-wide searches for orthologs in plants. BMC Genom 2008;9:183.

12. Conte MG, Gaillard S, Lanau N, Rouard M, Perin C. GreenPhylDB: a database for plant comparative genomics. Nucleic Acids Res 2008;36:D991-8.

13. Copani A, Uberti D, Sortino MA, Bruno V, Nicoletti F, Memo M. Activation of cell-cycle-associated proteins in neuronal death: a mandatory or dispensable path? Trends Neurosci 2001;24:25-31.

14. Cui H, Levesque MP, Vernoux T, Jung JW, Paquette AJ, Gallagher KL, et al. An evolutionarily conserved mechanism delimiting SHR movement defines a single layer of endodermis in plants. Science 2007;316:421-5.

15. de Dorlodot S, Forster B, Pages L, Price A, Tuberosa R, Draye X. Root system architecture: opportunities and constraints for genetic improvement of crops. Trends Plant Sci 2007;12:474-81.

16. Debi RB, Mushika J, Takeda S, Miyao A, Hirochika H, Ichii M. Isolation and characterization of a short lateral root mutant in rice (Oryza sativa L.). Plant Sci 2003;165:895-903.

17. Demidchik V, Essah PA, Tester M. Glutamate activates cation currents in the plasma membrane of Arabidopsis root cells. Planta 2004;219:167-75.

18. Di Laurenzio L, Wysocka-Diller J, Malamy JE, Pysh L, Helariutta Y, Freshour G, et al. The SCARECROW gene regulates an asymmetric cell division that is essential for generating the radial organization of the Arabidopsis root. Cell 2004;86:423-33.

19. Dolan L, Janmaat K, Willemsen V, Linstead P, Poethig S, Roberts $\mathrm{K}$, et al. Cellular organisation of the Arabidopsis thaliana root. Development 1993;119:71-84.

20. Droc G, Ruiz M, Larmande P, Pereira A, Piffanelli P, Morel JB, et al. OryGenesDB: a database for rice reverse genetics. Nucleic Acids Res 2006;34:D736-40.

21. Dubrovsky JG, Rost TL, Colon-Carmona A, Doerner P. Early primordium morphogenesis during lateral root initiation in Arabidopsis thaliana. Planta 2001;214:30-6.
22. Eckardt NA. Foolish seedlings and DELLA regulators: the functions of rice SLR1 and Arabidopsis RGL1 in GA signal transduction. Plant Cell 2002;14:1-5.

23. Evans A, David E. Aerenchyma formation. New Phytol 2004;161:35-49.

24. Falasca G, Zaghi D, Possenti M, Altamura MM. Adventitious root formation in Arabidopsis thaliana thin cell layers. Plant Cell Rep 2004;23:17-25.

25. Fujii Y. Studies on the regularity of root growth in rice and wheat plants. Agri Bull Saga Univ 1961;12:1-117.

26. Fukaki H, Nakao Y, Okushima Y, Theologis A, Tasaka M. Tissuespecific expression of stabilized SOLITARY-ROOT/IAA14 alters lateral root development in Arabidopsis. Plant J 2005;44:382-95.

27. Fustuhara Y, Kitano H. Inheritance of a root-growth inhibiting mutant in rice. Rice Genet Newslett 1985;2:70-1.

28. Galway ME, Masucci JD, Lloyd AM, Walbot V, Davis RW, Schiefelbein JW. The TTG gene is required to specify epidermal cell fate and cell patterning in the Arabidopsis root. Dev Biol 1994;166:740-54.

29. Grierson C, Schiefelbein J. Root hairs. In: Meyerowitz E, editor. The Arabidopsis book. Rockville: American Society of Plant Biologists; 2002.

30. Haecker A, Gross-Hardt R, Geiges B, Sarkar A, Breuninger H, Herrmann M, et al. Expression dynamics of WOX genes mark cell fate decisions during early embryonic patterning in Arabidopsis thaliana. Development 2004;131:657-68.

31. Hao Z, Ichii M. A mutant RM109 of rice (Oryza sativa L.) exhibiting altered lateral root initiation and gravitropism. Jpn J Crop Sci 1999;68:245-52.

32. Helariutta Y, Fukaki H, Wysocka-Diller J, Nakajima K, Jung J, Sena $\mathrm{G}$, et al. The SHORT-ROOT gene controls radial patterning of the Arabidopsis root through radial signaling. Cell 2000;101:555-67.

33. Hochholdinger F, Park WJ, Sauer M, Woll K. From weeds to crops: genetic analysis of root development in cereals. Trends Plant Sci 2004;9:42-8.

34. Hochholdinger F, Woll K, Sauer M, Dembinsky D. Genetic dissection of root formation in maize (Zea mays) reveals root-type specific developmental programmes. Ann Bot (Lond) 2004;93:359-68.

35. Hong SW, Aoki T, Kitano H, Satoh H, Nagato Y. Phenotypic diversity of 188 rice embryo mutants. Dev Genet 1995;16:298 310 .

36. Ichii M, Ishikawa M. Genetic analysis of newly induced short-root mutants in rice (Oryza sativa L.). Breed Sci 1997;47:121-5.

37. Inukai $Y$, Miwa $M$, Nagato $Y$, Kitano $H$, Yamauchi A. Characterization of rice mutants deficient in the formation of crown roots. Breed Sci 2001;51:123-9.

38. Inukai $Y$, Miwa $M$, Nagato $Y$, Kitano H, Yamauchi A. RRL1, RRL2 and CRL2 loci regulating root elongation in rice. Breed Sci 2001;51:231-9.

39. Inukai Y, Sakamoto T, Ueguchi-Tanaka M, Shibata Y, Gomi K, Umemura I, et al. Crown rootless1, which is essential for crown root formation in rice, is a target of an AUXIN RESPONSE FACTOR in auxin signaling. Plant Cell 2005;17:1387-96.

40. Itoh J, Nonomura K, Ikeda K, Yamaki S, Inukai Y, Yamagishi H, et al. Rice plant development: from zygote to spikelet. Plant Cell Physiol 2005;46:23-47.

41. Jia L, Zhang B, Mao C, Wu P, Wu Z. OsCYT-INV1 for alkaline/ neutral invertase is involved in root cell development and reproductivity in rice (Oryza sativa L.). Planta 2008;228:51-9.

42. Jiang K, Feldman LJ. Regulation of root apical meristem development. Annu Rev Cell Dev Biol 2005;21:485-509.

43. Jiang K, Meng YL, Feldman LJ. Quiescent center formation in maize roots is associated with an auxin-regulated oxidizing environment. Development 2003;130:1429-38. 
44. Jiang H, Wang S, Dang L, Wang S, Chen H, Wu YR, et al. A novel short-root gene encodes a glucosamine acetyltransferase required for maintaining normal root cell shape in rice. Plant Physiol 2005;138:232-42.

45. Johnson AA, Hibberd JM, Gay C, Essah PA, Haseloff J, Tester M, et al. Spatial control of transgene expression in rice (Oryza sativa L.) using the GAL4 enhancer trapping system. Plant J 2005;41:779-89.

46. Kamiya N, Itoh J, Morikami A, Nagato Y, Matsuoka M. The SCARECROW gene's role in asymmetric cell divisions in rice plants. Plant J 2003;36:45-54.

47. Kamiya N, Nagasaki H, Morikami A, Sato Y, Matsuoka M. Isolation and characterization of a rice WUSCHEL-type homeobox gene that is specifically expressed in the central cells of a quiescent center in the root apical meristem. Plant J 2003;35:42941.

48. Kamoshita A, Wade J, Ali L, Pathan S, Zhang J, Sarkarung S, et al. Mapping QTLs for root morphology of a rice population adapted to rain fed lowland conditions. Theor Appl Genet 2002;104:880-93.

49. Kamoshita A, Zhang J, Siopongco J, Sarkarung S, Nguyen HT, Wade LJ. Effects of phenotyping environment on identification of quantitative trait loci for rice root morphology under anaerobic conditions. Crop Sci 2002;42:255-65.

50. Kawashima C, Ishihara K, Ogura T. On the development of crown roots in various growth stages of the rice plant. Proc Crop Sci Soc Jpn 1973;42:197-206.

51. Kawata S, Ishihara H. Studies on the root hairs in rice plants. Proc Crop Sci Soc Jpn 1959;27:341-48.

52. Kawata S, Lai KC. On the meristematic state of the endodermis in the crown roots of rice plants. Proc Crop Sci Soc Jpn 1964;34:210-6.

53. Kawata S, Matsui K. On the cortex formation in the apical meristems of the elongating crown roots of rice plants. Proc Crop Sci Soc Jpn 1977;46:403-13.

54. Kawata S, Shibayama H. On the lateral root primordia formation in the crown roots of rice plants. Proc Crop Sci Soc Jpn 1965;33:423-31.

55. Kawata S, Soejima M. On superficial root formation in rice plants. Proc Crop Sci Soc Japan 1974;43:354-74.

56. Kawata S, Yamazaki K, Ishihara H, Shibayama H, Lai KC. Studies on root system formation in rice plants in a paddy field: an example of its relationship with the growth stage. Proc Crop Sci Soc Jpn 1963;33:168-80.

57. Kawata S, Nishimaki K, Yamazaki K. The apical structure of crown roots in rice plants. Jpn J Crop Sci 1977;46:393-402.

58. Kawata S, Suzuki S, Yamazaki K. The detachment of the "primary root caps" in rice plants. Jpn J Crop Sci 1979;48:303-10.

59. Kim DW, Lee SH, Choi SB, Won SK, Heo YK, Cho M, et al. Functional conservation of a root hair cell-specific cis-element in angiosperms with different root hair distribution patterns. Plant Cell 2006;18:2958-70.

60. Kono Y, Igeta M, Yamada N. Studies on the developmental physiology of the lateral roots in rice seminal roots. Proc Crop Sci Soc Jpn 1972;41:192-204.

61. Laplaze L, Parizot B, Baker A, Ricaud L, Martiniere A, Auguy F, et al. GAL4-GFP enhancer trap lines for genetic manipulation of lateral root development in Arabidopsis thaliana. J Exp Bot 2005;56:2433-42.

62. Lee MM, Schiefelbein J. WEREWOLF, a MYB-related protein in Arabidopsis, is a position-dependent regulator of epidermal cell patterning. Cell 1999;99:473-83.

63. Li Z, Mu P, Li C, Zhang H, Li Z, Gao Y, et al. QTL mapping of root traits in a doubled haploid population from a cross between upland and lowland japonica rice in three environments. Theor Appl Genet 2005;110:1244-52.
64. Li J, Zhu S, Song X, Shen Y, Chen H, Yu J, et al. A rice glutamate receptor-like gene is critical for the division and survival of individual cells in the root apical meristem. Plant Cell 2006;18:340-9.

65. Liang Z, Ichii M. Morphological characterization of the seedling of short-root mutant LM10 selected from rice (Oryza sativa L., IR8). Jpn J Crop Sci 1995;65:473-8.

66. Lim J, Helariutta Y, Specht CD, Jung J, Sims L, Bruce WB, et al. Molecular analysis of the SCARECROW gene in maize reveals a common basis for radial patterning in diverse meristems. Plant Cell 2000;12:1307-18.

67. Liu H, Wang S, Yu X, Yu J, He X, Zhang S, et al. ARL1, a LOBdomain protein required for adventitious root formation in rice. Plant J 2005;43:47-56.

68. Masucci JD, Rerie WG, Foreman DR, Zhang M, Galway ME, Marks MD, et al. The homeobox gene GLABRA2 is required for position-dependent cell differentiation in the root epidermis of Arabidopsis thaliana. Development 1996;122:1253-60.

69. Meijer AH, Scarpella E, van Dijk EL, Qin L, Taal AJ, Rueb S, et al. Transcriptional repression by Oshox1, a novel homeodomain leucine zipper protein from rice. Plant J 1997;11:263-76.

70. Mergemann H, Sauter M. Ethylene induces epidermal cell death at the site of adventitious root emergence in rice. Plant Physiol 2000;124:609-14.

71. Morita S, Nemoto K. Morphology and anatomy of rice roots with special reference to coordination in organo- and histogenesis. In: Baluska F, et al, editor. Structure and function of roots. Dordrecht: Kluwer Academic; 1995. p. 75-86.

72. Okushima Y, Overvoorde PJ, Arima K, Alonso JM, Chan A, Chang $\mathrm{C}$, et al. Functional genomic analysis of the AUXIN RESPONSE FACTOR gene family members in Arabidopsis thaliana: unique and overlapping functions of ARF7 and ARF19. Plant Cell 2005; 17:444-63.

73. Paquette AJ, Benfey PN. Maturation of the ground tissue of the root is regulated by gibberellin and SCARECROW and requires SHORT-ROOT. Plant Physiol 2005;138:636-40.

74. Qu Y, Mu P, Zhang H, Chen CY, Gao Y, Tian Y, et al. Mapping QTLs of root morphological traits at different growth stages in rice. Genetica 2008;133:187-200.

75. Sakamoto T, Miura K, Itoh H, Tatsumi T, Ueguchi-Tanaka M, Ishiyama $\mathrm{K}$, et al. An overview of gibberellin metabolism enzyme genes and their related mutants in rice. Plant Physiol 2004;134:1642-53.

76. Sarkar AK, Luijten M, Miyashima S, Lenhard M, Hashimoto T, Nakajima $\mathrm{K}$, et al. Conserved factors regulate signalling in Arabidopsis thaliana shoot and root stem cell organizers. Nature 2007;446:811-4.

77. Sasaki O, Yamazaki K, Kawata S. The relationship between the diameters and the structures of lateral roots in rice plants. Jpn J Crop Sci 1984;53:169-75.

78. Scarpella E, Rueb S, Boot KJ, Hoge JH, Meijer AH. A role for the rice homeobox gene Oshox1 in provascular cell fate commitment. Development 2000;127:3655-69.

79. Scarpella E, Boot KJ, Rueb S, Meijer AH. The procambium specification gene Oshox 1 promotes polar auxin transport capacity and reduces its sensitivity toward inhibition. Plant Physiol 2002;130:1349-60.

80. Scarpella E, Rueb S, Meijer AH. The RADICLELESS1 gene is required for vascular pattern formation in rice. Development 2003;130:645-58.

81. Scheres B, Benfey P, Dolan L. Root development. In: Meyerowitz E, editor. The Arabidopsis book. Rockville: American Society of Plant Biologists; 2002.

82. Sergeeva LI, Keurentjes JJ, Bentsink L, Vonk J, van der Plas LH, Koornneef M, et al. Vacuolar invertase regulates elongation of Arabidopsis thaliana roots as revealed by QTL and mutant analysis. Proc Natl Acad Sci USA 2006;103:2994-9. 
83. Shuai B, Reynaga-Pena CG, Springer PS. The lateral organ boundaries gene defines a novel, plant-specific gene family. Plant Physiol 2002;129:747-61.

84. Sorin C, Bussell JD, Camus I, Ljung K, Kowalczyk M, Geiss G, et al. Auxin and light control of adventitious rooting in Arabidopsis require ARGONAUTE1. Plant Cell 2005;17:1343-59.

85. Steele KA, Price AH, Shashidhar HE, Witcombe JR. Marker-assisted selection to introgress rice QTLs controlling root traits into an Indian upland rice variety. Theor Appl Genet 2006;112:208-21.

86. Steffens B, Sauter M. Epidermal cell death in rice is regulated by ethylene, gibberellin, and abscisic acid. Plant Physiol 2005;139:713-21.

87. Subbaiah CC, Sachs MM. Molecular and cellular adaptations of maize to flooding stress. Ann Bot (Lond) 2003;91(Spec No):119-27.

88. Suzuki N, Takeda S, Ichii M. Morphological and physiological characteristics of a root-hairless mutant in rice (Oryza sativa L.). Plant Soil 2003;255:9-17.

89. Umeda M, Umeda-Hara C, Yamaguchi M, Hashimoto J, Uchimiya H. Differential expression of genes for cyclin-dependent protein kinases in rice plants. Plant Physiol 1999;119:31-40.

90. Walch-Liu P, Liu LH, Remans T, Tester M, Forde BG. Evidence that L-glutamate can act as an exogenous signal to modulate root growth and branching in Arabidopsis thaliana. Plant Cell Physiol 2006;47:1045-57.

91. Wan J, Nakazaki T, Ikehashi H. Analyses of genetic loci for diameter of seminal root with marker genes in rice. Breed Sci 1996;46:75-7.
92. Wang H, Takeda S, Miyao A, Hirochika H, Ichii M. Isolation of a novel lateral-rootless mutant in rice (Oryza sativa L.) with reduced sensitivity to auxin. Plant Sci 2006;170:70-7.

93. Wolfe KH, Gouy M, Yang YW, Sharp PM, Li WH. Date of the monocot-dicot divergence estimated from chloroplast DNA sequence data. Proc Natl Acad Sci USA 1989;86:6201-5.

94. Yao S, Takeda S, Ichii M. Isolation and characterization of an abscisic acid-insensitive mutation that affects specifically primary root elongation in rice (Oryza sativa L.). Plant Sci 2003;164:971-8.

95. Yao S, Mushika J, Takeda S, Ichii M. The short-root mutation srt5 defines a sugar-mediated root growth in rice (Oryza sativa L.). Plant Sci 2004;167:49-54.

96. Yi X, Liang Z, Kawasaki S, Kuroda S, Ichii M, Ashikawa I. Construction of a contig with transformation competent subclones in the gene region of Srt3, responsible for the root growth in rice. In Plant, Animal and Microbe Genomes X Conference, San Diego, USA; 2002.

97. Zheng HG, Babu RC, Pathan MS, Ali L, Huang N, Courtois B, et al. Quantitative trait loci for root-penetration ability and root thickness in rice: comparison of genetic backgrounds. Genome 2000;43:53-61.

98. Zheng BS, Yang L, Zhang WP, Mao CZ, Wu YR, Yi KK, et al. Mapping QTLs and candidate genes for rice root traits under different water-supply conditions and comparative analysis across three populations. Theor Appl Genet 2003;107:1505-15.

99. Zheng BS, Yang L, Mao CZ, Zhang WP, Wu P. QTLs and candidate genes for rice root growth under flooding and upland conditions. Yi Chuan Xue Bao 2006;33:141-51. 